NRRI 95-10

\title{
THE USE OF INFORMATION SYSTEMS TO TRANSFORM UTILITIES AND REGULATORY COMMISSIONS: THE APPLICATION OF GEOGRAPHIC INFORMATION SYSTEMS
}

by

David W. Wirick
The National Regulatory
Research Institute

David C. Wagman

Convergent Group
Glenn E. Montgomery

Convergent Group

James Spiers

Consultant/Attorney

September 1995

\author{
THE NATIONAL REGULATORY RESEARCH INSTITUTE \\ The Ohio State University \\ 1080 Carmack Road \\ Columbus, Ohio 43210-1002 \\ $614 / 292-9404$
}

This report was prepared by The National Regulatory Research Institute (NRRI) with funding provided by participating member state commissions of the National Association of Regulatory Utility Commissions (NARUC). The Convergent Group donated its time to this study. The views and opinions of the authors do not necessarily state or reflect the views, opinions, or policies of the NRRI, the NARUC, or any state commissions. Further, any mention of products or services in this report does not constitute an endorsement by the authors, the NRRI, the NARUC, or NARUC member commissions. 
MPAM 


\section{DISClaAmIER}

Portions of this document may be illegible in electronic image products. Images are produced from the best available original document. 


\section{EXECUTIVE SUMMARY}

Technology and the competitive markets made possible by technology have radically reshaped the public utility industry and its regulation. One set of technologies that has the potential to assist utilities remain financially viable in competitive markets and help utilities and regulators to better serve the public is information technology.

Typically, utilities have focused on reducing costs as a primary means of competing with rivals. Unfortunately, the ability to become the low-cost provider is impacted by many irreversible investment decisions made during less-competitive times. As a result, most utilities will need to make new investments that better position the company to provide competitive services that are valued by customers. Investment in information systems is one strategy that allows utilities to better identify and track potential customers and their needs and to provide many new services specifically tailored to their needs.

In order to make optimal use of information, utilities, and to some extent regulatory commissions, will need to make the transition to being "information-based" organizations. Information-based organizations recognize that, although they produce a tangible product (utility service), the most important product of the organization is information. Information-based organizations are "flatter" than traditional organizations; rely on the expertise of those who create new information and knowledge; employ task-focused teams as the basic unit of work; and transform data into information, which allows informed decisions to replace opinion. Through the adroit use of information, information-based organizations identify the needs of those they serve, adapt their work and organization to the optimal service of their customers, and generate a fair return for their shareholders.

Making the transition to an information-based organization is a challenge. It requires building powerful and flexible information systems that can bring together internal and external sources of information in a system with graphic, analytic, modeling, and communication capabilities. It requires a careful evaluation of 
information requirements, effective system-development strategies, and thorough costbenefit analyses.

Those cost-benefit analyses of information systems will need to include consideration of the strategic benefits of information systems since those systems may be employed to attract new customers, to support customer-specific programs and services, and to develop a better understanding of a competitor's capabilities. Indeed, labor savings typically account for only thirty to forty percent of projected system benefits. The five recommended steps of information system cost-benefit analysis are determination of baseline costs, development of a strategic implementation plan, determination of benefits, comparison of costs and benefits, and performance of sensitivity analysis and risk assessment.

Because geography is such an important part of an electric, natural gas, telecommunications, or water utility's service delivery system, Geographic Information Systems (GIS), which encompass utility transmission and distribution facilities, have been employed by many utilities and are being planned by many others. One Convergent Group estimate is that utilities may invest as much as $\$ 48$ billion in GIS technology and data in the next decade. Public utility commissions have also invested in GIS. As a result, this report highlights GIS as a key information technology that has the capability to assist utilities and regulatory commissions in their transition to information-based organizations. GIS has been employed to replace paper maps and records and is now being used to provide utilities and commissions with strategic advantages. Among the key trends driving the need and specific planning for the use of information systems like GIS are downsizing, the rise of outsourcing as an option for system development and operation, safety and regulatory compliance issues, environmental impacts and siting, new competition and competitive alternatives, deregulation, and reengineering.

Reengineering focuses on the outcome of work processes as opposed to total quality management (TQM), which focuses on the processes themselves. Information systems, like GIS, can provide support for these efforts necessary to fundamentally 
redesign business processes and support strategic business decisions particularly when acceleration of these efforts is critical.

Under traditional, ratebase/rate-of-return regulation, options for the regulatory treatment of information system investments include expensing costs immediately, amortizing them over a longer period, or including them in the ratebase. Other traditional issues include determination of the prudency of information system investments, the establishment of the appropriate depreciable life, and the allocation of costs and benefits between regulated and unregulated business segments. Under incentive regulation and price-cap forms of regulation, the regulatory treatment of utility information system investments will only be initially important as regulators set baseline rates or price caps. It will be difficult for regulators to separate the benefits of information systems into those that serve the interests of captive ratepayers and those that position the utility to compete in new environments.

The biggest challenge for utilities and regulators will not be to find ways to use information to benefit consumers; the opportunities to productively use information to benefit customers are virtually endless. The biggest challenges will be funding, designing and building effective systems, performing adequate cost-benefit analyses, and convincing others that there will be long-term payoffs for many information-systems investments. 



\section{TABLE OF CONTENTS}

Executive Summary $\ldots \ldots \ldots \ldots \ldots \ldots \ldots \ldots \ldots \ldots \ldots \ldots \ldots \ldots \ldots \ldots \ldots$ ii

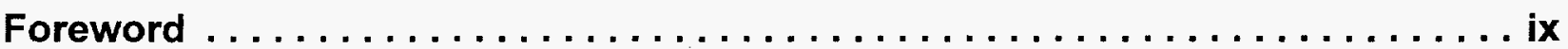

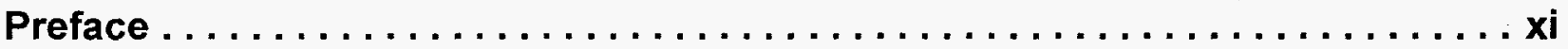

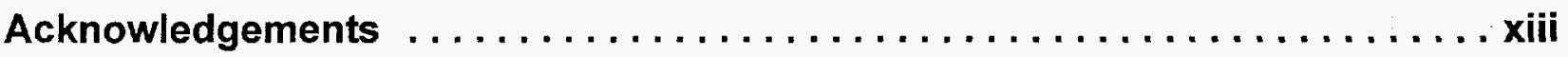

Chapter One

The Information Imperative $\ldots \ldots \ldots \ldots \ldots \ldots \ldots \ldots \ldots \ldots \ldots$

Chapter Two

The Increasing Primacy of Information $\ldots \ldots \ldots \ldots \ldots \ldots \ldots \ldots 7$

Chapter Three

Transition to an Information-Based Organization $\ldots \ldots \ldots \ldots \ldots \ldots 21$

Chapter Four

The Application of GIS Technology $\ldots \ldots \ldots \ldots \ldots \ldots \ldots \ldots \ldots, 41$

Chapter Five

Utility GIS Investments: Key Business and Regulatory Drivers . . . . 57

Chapter Six

The Application of GIS in Support of Reengineering $\ldots \ldots \ldots \ldots \ldots 69$

Chapter Seven

Regulatory Issues 



\section{FOREWORD}

NARUC has, for good reason, recently taken a strong interest in the use of information systems by utilities and by commissions themselves. This report was prepared to assist states in their efforts to understand and employ information systems in today's rapidly changing utility and regulatory environments. It presents a strong case for the use of information technologies to transform utility and commission operations.

In preparing this report, the NRRI was aided by Glenn Montgomery and David Wagman of the Convergent Group, a consulting firm that works with many electric, natural gas, telecommunications, and water utilities in the use of Geographic Information Systems. James Spiers, a private consultant and attorney and former executive director of the Colorado Public Utilities Commission, also contributed. Their time and expertise were provided without charge to the NRRI.

Douglas N. Jones

Director

Columbus, Ohio

September 1, 1995 



\section{PREFACE}

As competition becomes a fact of life for utilities and for those who regulate them, a better understanding of information systems is critical. Information systems allow utilities and commissions to perform their jobs faster, better, and more effectively. Information systems may also hold the key to providing better customer service and, ultimately, to achieving enhanced competitiveness. One type of information system that has shown promise and which has been extensively invested in by utilities and regulatory commissions alike is Geographic Information Systems (GIS).

In the rapidly evolving utility environment, utilities and regulators will be faced with complex issues related to information systems. Those issues include effective costbenefit determination, the choice of implementation method, the restructuring of organizations to optimally use information, the integration of information systems, the retraining of staff to perform in an information-intense environment, and the identification of strategic opportunities through the effective application of information systems that integrate data from a variety of sources. Without doubt, in the years to come information systems will be a major component of utility investments and will be put to use to assist them find and hold a competitive advantage. Regulators, too, will put these systems to work to enhance their own efficiency and effectiveness, and to achieve their ultimate public service mission. Those utilities and commissions that are the most successful will be those that most effectively gather, distribute, and use information. Gaining a better understanding of computer hardware capabilities and a better knowledge of what type and how software applications are used will be KEY.

The NARUC has taken a strong interest in computerized information systems, as indicated by its sponsorship of the first NARUC Regulatory Symposium on Computer Information Systems held in October 1995 in Colorado Springs. This report augments the NARUC's efforts to improve the understanding of computerized information systems.

I appreciate the work of the NRRI and the Convergent Group to produce this report and their support of the NARUC and its information systems endeavors.

I believe that you will find the report interesting, informative, and useful.

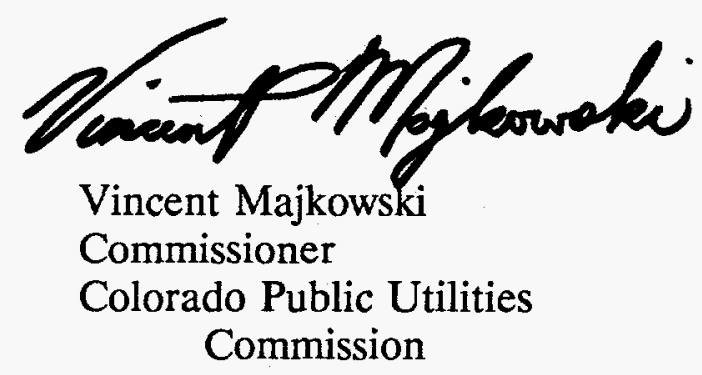




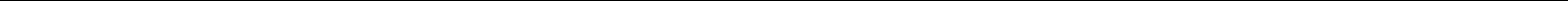




\section{ACKNOWLEDGMENTS}

The authors would like to express their thanks to the many persons involved in the creation and production of this report and, in particular, to Commissioner Vince Majkowski of the Colorado Public Utilities Commission who took the time to review the draft report and to prepare the preface. The report also benefitted from the careful and expert review of Dr. Doug Jones and Dr. Ray Lawton of the NRRI and helpful editing by Dr. Fran Sevel. Jacquie Shepherd ably, as always, prepared the final version of the report. We also appreciate the support for this project of the NARUC Subcommittee of Executive Directors. 


\section{CHAPTER 1}

\section{THE INFORMATION IMPERATIVE}

Ultimately, I see three types of utilities: aggressors, defenders, and bait! These labels will in the long run be assigned based on each company's financial strength, strategic preparedness, competitive position and the effects of regulatory policy.

-- Remarks by James A. Carrigg, CEO, New York State Electric and Gas, at the EXNET Mergers \& Acquisitions Symposium, February 3, 1995

A generation of reform at both the state and the federal levels has altered the utility landscape so profoundly that statements such as this are no longer regarded as brash hyperbole but as insights into the utility industry of the future.

As James Carrigg notes, financial strength, strategic preparedness, competitive positioning, and regulatory policy will be the principal factors determining a utility's success and failure. Success will not depend upon service franchises granted and protected by force of law. Nor will it depend upon building and accumulating vast quantities of hard assets whose cost can be included in a rate base and recovered from captive customers. Instead, competitiveness will depend upon how successfully a utility acquires, analyzes, and uses information about itself, its customers, and its market territory.

Increasingly, the marketplace is viewed as an efficient regulator for a number of utility functions newly subjected to market competition. Further complicating the utility business environment is the fact that electrons, molecules, and light waves--the bases for utility service--are often viewed as commodity products. The quality of these products has become so uniform across North America that, to date, price and availability have become the primary criteria in their purchase for most consumers. Electricity generated in New York state is the same as that generated in California. Ironically, the utility industry's success at delivering such uniformly good products 
(natural gas, electricity, telecommunications, and, generally speaking, water) may be contributing to the wrenching change they now are enduring. After all, as North American manufacturers compete in the global marketplace, they are increasingly sensitive to the cost of their raw inputs. Utility services are counted as elements of production by manufacturers who must aggressively manage these costs to keep their products competitive in North American and global markets. Because utilities principally sell what is in essence a commodity in an environment where regulatory reform and competition are becoming facts of life, and where technology has expanded the ability of end users to choose their suppliers, utilities face strong pressures to keep their costs as low as possible.

But not every utility can be the lowest-cost provider. Therefore, for most utilities competitive success will hinge not on how cheaply the commodity is priced, but instead on how well enhanced services are marketed, how responsive utilities are at meeting their customers' requests, how aggressive utilities are at capturing new business or defending existing business,

For most utilities, competitive. success will hinge on how responsive utilties are at meeting theit customers' requests. and what treatment regulators afford the investments in technology that utilities will continue to make through the final years of the century.

In the past several years, technology has had a significant and, some would argue, a fundamentally destabilizing impact on the regulated public utilities. Those changes in technology have contributed to a radical restructuring of the utility industry and the potential for sweeping changes in regulatory regimes.

Those technological innovations have changed the face of the regulated utilities and of regulation itself. Although traditional production and delivery technologies may continue to evolve and impact utility markets, technological changes in production and product distribution may plateau. The next set of revolutionary, technology-driven changes for utility managers and regulators, therefore, may come from changes in 
information technologies. Those changes in information technologies may not alter the fundamental structure of the utility industries but will allow utilities and regulators to navigate their way through new markets and new regulatory requirements.

This report examines the potential impact of information technologies on regulated utilities and on the process of regulation. It attempts to answer the following questions:

- How can information technologies change the way commissions and utilities provide services to their customers?

- How can utilities and regulatory commissions use information systems to transform the ways in which they operate?

- What types of information are required by utilities and regulators in the new, more competitive utility marketplace?

- How can utilities and regulators make the transition to information-based organizations and make decisions about the regulatory treatment of investments in information technologies?

Electric, natural gas, telecommunications, and water utilities have an important geographical dimension, perhaps more so than many other industries. The lexicon of these industries is filled with geography. Generating plants are "sited;" natural gas is drawn from "fields;" customers are in service "territories;" transmission lines, telephone wires and pipelines follow carefully drawn "corridors;" and electric utilities are interconnected by "grids." Indeed, the telecommunications industry is embedded in geographic concepts such as local calling exchanges, extended area service, and interLATA and intraLATA toll routes. In the day-to-day business of running a utility, meter readers walk routes, repair crews use maps to locate facilities, and, when an emergency arises, outage or service interruptions can be tracked and monitored on wall-sized graphical displays as calls are received from affected customers, and as designers and engineers draft service upgrades and expansions. 
Because geography is such an important part of an electric, natural gas, telecommunications or water utility, computer-based Geographic Information Systems (GIS) and related Automated Mapping/Facilities Management (AM/FM) systems are emerging as core technologies that form the basis for managing an ever-expanding variety of formerly manual or paper-based tasks.

For example, a GIS integrated with other computer-based operating systems may allow a customer service representative to take a trouble outage report, determine the extent of the outage and its probable cause, assign a work crew to repair the trouble and estimate when the customer's service is likely to be restored--all in the course of a single telephone conversation. In the course of a second round of telephone conversations, the customer service representative can identify all customers potentially affected by the outage and inform those customers of the duration of the service interruption. An electric utility could also program its Customer Information System to automatically telephone customers with a wake-up call--when requested-if the power outage will extend overnight and disrupt electric alarm clocks. Similarly, when a request for new or extended utility service is received, a customer service representative equipped with a GIS may be able to make all of the necessary arrangements while the customer remains on the phone line. In some instances, this may cut by weeks the time typically needed by some utilities to establish service.

The extent of the utility investment in GIS is expected to be staggering. For example, some 1,100 gas utilities in the United States alone represent $\$ 120+$ billion in assets; their potential GIS technology and data purchases through the year 2005 may total $\$ 8+$ billion. ${ }^{1}$ Similarly, the U.S. electric industry represents more than 3,000 organizations and companies, which own and manage almost $\$ 400$ billion in installed plant assets; they are poised to invest as much as $\$ 18+$ billion on GIS technology and data within the next eight to ten years. Likewise, in the next decade the U.S. telephone

${ }^{1}$ Ed Forrest, Glenn E. Montgomery, Ginger M. Juhl, Intelligent Infrastructure Workbook: A Management-Level Primer on GIS, A-E-C Automation Newsletter, 1990 and updated from 1995 Convergent Group unpublished research. All of the data in this paragraph are drawn from this source. 
industry, which accounts for more than one-third of all telephones on the planet, is estimated to make GIS technology and data purchases approaching $\$ 22+$ billion.

Because of the inherent geographic focus of utilities and the substantial (actual and potential) utility investments in GIS, this report will focus on GIS as an example of the types of information systems that can be used by utilities and regulatory commissions. GIS is not the only information technology available nor is it appropriate in every instance or the solution for every problem. Nonetheless,

GIS is not the only intormation technology available nor is it approportate in every instance or the solution tor eveny problem. Nonetheless, it is a powerful tool that has shown the capability to be applied to the benefit of customers, utilities, and regulators:

it is a powerful tool that has shown the capability to be applied to the benefit of customers, utilities, and regulators.

The second chapter of the report provides some general information about information systems and the impact of the widespread availability of information on organizations and organizational design. Chapter Three explores the challenging process of converting an organization to an information-based organization. Chapters Four and Five set out GIS as an example of the use of information technologies to transform the way utilities and commissions operate. Chapter Six describes the use of GIS and other information systems to support organizational reengineering efforts. Chapter Seven examines the regulatory treatment of information systems.

It is clear that information technologies cannot solve every utility or commission

Information systems have reached a point of maturity that not only allows them to speed up previous manual processes but to fundamentally. change the work that is done and create dramatic changes in the quality of customer service. problem; utility managers and regulators will always need to make decisions with limited information. It is also clear that good information systems are expensive to create and maintain, a factor that is particularly troublesome in this era of dramatic utility and regulatory 
commission cost-cutting. But information systems have reached a point of maturity that not only allows them to speed up previous manual processes but to fundamentally change the work that is done and create dramatic changes in the quality of customer service.

The convergence of three interrelated factors allows information systems to assume such a pivotal role in the operation of utilities and their regulation. Those factors are (1) the development of new information technologies, (2) the emergence of the information-based organization and the preeminence within that organization of the knowledge worker, and (3) changes in utility markets and regulatory commission roles. These factors cause information to be the most important commodity for both the utility and the regulator. Each of the factors is discussed in turn in the following chapter.

In the past, information systems were used to support the mission of the organization by automating manual processes and creating efficiency gains. In the future, as information is recognized as the most valuable resource of the organization (second only, perhaps, to its people), information systems will be employed to create a competitive position. In the utility industry, the need to gain a competitive edge through superior and innovative customer service will cause utilities to scramble to hone their ability to effectively use information systems like GIS in the competitive wars. As regulators adapt to the new utility environment, they will rely on new information technologies including GIS to define and accomplish their missions as well. 
CHAPTER TWO

\section{THE INCREASING PRIMACY OF INFORMATION}

\section{The Impact of New Information Technologies}

The increase in speed and capacity of computers has allowed larger and more complex applications to be performed and for those applications to be performed at the employee desktop rather than by a central mainframe. Now, more data can be brought together, more sophisticated models can be run, more complicated scenarios can be analyzed, and, through it all, individual staff members are less dependent on central processing and access to centrally-provided information. We have entered an era of "do-it-yourself" analysis, and, as we will see later, desktop computers now have the ability to create visual displays of the results of the analysis, displays that can be used to facilitate the analysis or to assist the analyst to communicate with others.

But the sheer speed and capacity of computers is only one of the technological factors that have increased the transformative power of information systems.

Peripheral equipment (telephones, copiers, printers, facsimile machines, and scanners) has also become "smarter" and better able to be integrated into information systems. Improvements in telemetry (automatic measurement) and home automation systems will provide customers with the information to make price-sensitive energy consumption choices. New linking technologies, such as fiber-optic cable, Integrated Services Digital Network (ISDN), ${ }^{1}$ and asynchronous transfer mode (ATM) ${ }^{2}$ can link these smart

\footnotetext{
'ISDN is the "international standard for transmitting voice, video, and data to support a wide range of service over the public telephone lines." Kenneth C. Laudon and Jane P. Laudon, Essentials of Management Information Systems (Englewood Cliffs, NJ: Prentice Hall, 1995), 241.

${ }^{2}$ ATM is a "networking technology that parcels information into 8-bit "cells," allowing data to be transmitted between computers of different vendors at any speed." Laudon and Laudon, Essentials of Management Information Systems, 232.
} 
peripherals and computers. ${ }^{3}$ A variety of information services providers, including traditional telephone companies, long-distance carriers, cable television providers, and other utilities are vying for the right to provide information across these networks. ${ }^{4}$

New software is also available to change the way utilities and commissions operate. For example, workgroup software (groupware) is designed to improve communications between groups; move information, such as images and documents among people; and automate the work process. ${ }^{5}$ Group conferencing software lets organizations create meetings that allow people to join in as their schedules permit. ${ }^{6}$ Group conferencing software does not attempt to replace human interaction but attempt to eliminate some of the shortcomings of traditional meetings; foster successful collaboration; and generate, consolidate, evaluate, and document ideas. ${ }^{7}$ Workflow automation software manages complex, interlocking tasks by employing rules-based logic to systemize and speed up business processes. ${ }^{8}$ And more applications of artificial intelligence (Al) are being developed and employed in a variety of business environments. These applications employ rule-based reasoning, case-based reasoning, or pattern matching (neural networks) ${ }^{9}$ and allow logic to be applied to masses of data. Competitive business organizations are also now employing "data warehouses," massive databases that provide insight into consumer behavior. According to Price Waterhouse ninety percent of large companies are building data

${ }^{3}$ Michael J. Miller, "The Changing Office," PC Magazine, June 14, 1994, 114.

4 Ibid.

${ }^{5}$ Rick Ayre and Ben Z. Gottesman, "Group Enabled," PC Magazine, June 14, 1994, 172.

6 Joe Salemi, "Let's Interface," PC Magazine, June 14, 1994, 191.

${ }^{7}$ Mary Ellen Kranz and Valerie I. Sessa, "Meeting Makeovers," PC Magazine, June 14, 1994, 205206.

${ }^{8}$ Michael A. Bragen, "Go with the Flow," PC Magazine, June 14, 1994, 253-254.

${ }^{9}$ Carol E. Brown, James Coakley, and Mary Ellen Phillips, "Neural Networks Enter the World of Management Accounting," Management Accounting, May 1995, 51. 
warehouses or plan to build them by the year $2000 .^{10}$

No discussion of information technologies would be complete without mentioning the Information Superhighway, which has been described as "the convergence of powerful processing, improved bandwidth, massive storage, and a social need to communicate."11 The key to the effectiveness of the Superhighway and other new information systems lies in that The rey o the eriectiveness or the Superiolivay and ot the new mom mation systems res in wat convergenee. Which allous o wide array of ofsparate dat a sources to be integrated and mined for usetul. heretotore naccessible, business intormation.

convergence, which allows a wide array of disparate data sources to be integrated and mined for useful, heretofore inaccessible, business information.

Utilities and regulatory commissions have begun to use these sophisticated systems. For example, the Electric Power Research Institute has designed technologies for fault location and reporting, staggered service restoration, automatic meter reading, remote service connection and disconnection, real-time pricing, direct load management, demand-side management, power brokering, and improved customer services. ${ }^{12}$ A pilot program sponsored by Entergy uses a real-time, fiber-optic network to provide two-way communications between the host utility and the customer. ${ }^{13}$ A number of utilities have employed Geographic Information Systems to help make marketing and other decisions. (See chapters Four and Five.)

Commissions have begun to apply information technologies to transform their operations as well. For example, the New York State Department of Public Service has 81.

${ }^{10}$ John Verity with Russell Mitchell, "A Trillion-Byte Weapon," Business Week, July 31, 1995, 80-

${ }^{11}$ Frank J. Derfler, Jr., "Powerful Convergence," PC Magazine, July 14, 1994, 140.

12 Peter Jaret, "Grabbing a Lane on the Information Superhighway," The EPRI Journal, January/February 1995, 25.

${ }^{13}$ Ibid., 22-24. 
undertaken initiatives to install a regulatory information data base, a Geographic Information System, and video-conferencing capability via a high-speed data link. ${ }^{14}$

These systems and applications mark the beginning of a revolution in the use of information systems by utilities and commissions. At one time, it was correct to say that our ability to generate data far surpassed our ability to acquire, analyze, retain, utilize, and transfer this information. ${ }^{15}$ But now, our ability to integrate and use information have progressed dramatically. The ability In the near term future, the aggressive and eftective use of information systems will be a requirement not an option for. competitive business organizations.

to create new, integrated information

systems is limited only by the human imagination. The ongoing convergence of powerful hardware, peripherals, software, linking technologies, and dramatic changes in utility operating environments will surely create new opportunities for the development and application of new information systems. Changes in utility markets and business organization will also likely produce new demands for effective, integrated information systems. In the near-term future, the aggressive and effective use of information systems will be a requirement, not an option for competitive business organizations. Most see the implementation of systems like GIS as a question of "when" not "if."

\section{The Emergence of the Information-Based Organization}

As technology has made information more available to business and government organizations, market conditions, such as global competition and short product lives,

\footnotetext{
${ }^{14}$ New York State Department of Public Service, "Information Resource Management Plan," August 1994, 21-22.

${ }^{15}$ Dr. Francine Sevel, "Responding to the Challenges of Tomorrow: Changes in the Dissemination of Clinical Information," Proceedings of the Collaborative Research in Allied Health Symposium (Columbus, $\mathrm{OH}$ : The Ohio State University School of Allied Medical Professions, 1986), 127.
} 
have required them to apply that information to strategic business decisions. Indeed, as the modern, post industrial economy has evolved, information has become central to the mission and survivability of any organization. Even though a tangible product may still be produced, successful organizations are in the information business--that is, they use information to create a competitive advantage. They are "information-based" organizations. $^{16}$

In addition to their use of information for competitive advantage, informationbased organizations have several unique characteristics. Those characteristics of information-based organizations are: ${ }^{17}$

- The ability to transform data into information. Informed decisions based on real information replace opinion.

- A flatter organization. In an information-based organization, there is no need for layers of managers whose only function is to create an interface between those who have data and those who make decisions.

- A large number of specialists in operating rather than central portions of the organization. Knowledge in an information-based organization lies at the lower levels of the organization in the minds of specialists who do the work of the organization.

- Task-focused teams as the basic unit of work. Departments serve as centers for training and for assignment of specialists. Specialists work together as a team to accomplish a specific, time-limited function.

- A reliance on self-discipline and individual responsibility.

Those organizations that use information as a competitive tool also hold different assumptions about information; they assume that information is to be shared and

\footnotetext{
${ }^{16}$ Peter F. Drucker, The New Realities (New York, NY: Harper and Row, Publishers, 1989), 207.

${ }^{17} \mathrm{Ibid} ., 207-220$.
} 
information is a source of knowledge and control. ${ }^{18}$ They resemble networks rather than hierarchies. ${ }^{19}$ They are characterized by a preponderance of information work (the creating and processing of information), which is performed by information workers (those who use, process, and

These knowledge workers are the keys to the information based: organization.

disseminate information) and

knowledge workers (those who create new information and knowledge). ${ }^{20}$ These knowledge workers are the keys to the information-based organization. They have three distinct roles. They interpret ever-expanding external knowledge bases, they serve as internal consultants to their organizations, and they evaluate, initiate, and promote change in the organization. ${ }^{24}$ Because of their roles, they are often autonomous and require different supervisory models than other workers. ${ }^{22}$

To be sure, the information-based organization will be a challenge for managers. Three of the most difficult challenges will be (1) continually training employees, (2) integrating knowledge work into organizations that are traditionally hierarchical, and (3) designing information systems that increase productivity without threatening high-level managers and professionals. ${ }^{23}$ It is possible to become an information-based organization without the use of sophisticated information technologies, ${ }_{1}^{24}$ but new information technologies provide powerful tools to drive the transition.

${ }^{18}$ Blake Ives and Sirkka L. Jarvenpaa, "Competing with Information: Empowering Knowledge Networks with Information Technology," The Knowledge Economy: The Nature of Information in the 21st Century, (Aspen, CO: Institute for Information Studies, 1993), 60.

${ }^{19}$ Ibid.

${ }^{20}$ Laudon and Laudon, Essentials of Management Information Systems, 340.

${ }^{21}$ Ibid., 355.

22 lbid.

${ }^{23}$ Ibid., 363.

${ }^{24}$ Peter F. Drucker, The New Realities, 212. 


\section{Changes in Utility Markets and Regulatory Commission Roles}

As the preceding section indicates, the survival of any organization, public or private, in a competitive or changing environment is dependent on the effective application of information to gain a strategic advantage through superior service. That dictum applies to utilities and regulatory commissions as well, particularly in these days of rapid change. In general, there are five ways that an organization can create a competitive advantage; it can: ${ }^{25}$

- Create a product that can easily be differentiated from those of its competitors

- Identify a specific target for a product that it can serve in a superior manner

- Create ties to customers that lock customers to the firm's products

- Create systems that link the company to its customers, distributors, or suppliers

- Become the low-cost producer.

For utilities, the focus most often is on the last method. The first four, however, are less impacted by prior infrastructure decisions and can, therefore, provide the best opportunities for improving the competitive position of the utility. As competition emerges in utility markets and as utilities and regulatory commissions become information-based organizations, information that supports the pursuit of a competitive advantage will become the most valuable commodity produced or controlled by utilities and commissions. In a competitive environment, prudent management and the production of a utility service will no longer be enough; in a competitive environment, utilities will need to leverage information resources and technologies to establish a competitive advantage over competitors.

${ }^{25}$ Laudon and Laudon, Management Information Systems, 47-53. 
Leveraging information requires more than automating office functions. Effectively leveraging information requires the integration of new data sources with powerful computing tools. For utilities, the effective application of information as a commodity may involve uses of information such as:

- Identifying customer needs and expectations and alternatives for service provision

- Identifying opportunities for service expansion

- Identifying vulnerable customers of competitors

- Evaluating capital investment decisions in order to maximize customer service

- Improving quality of service

- Restoring service in emergencies

- Targeting specific customers or potential customers with marketing campaigns

Interestingly, new technologies and data sets can aggressively support all of these predominantly geographically-based uses. The information necessary to support these new or developing systems may include information on pricing, market share, quality of service provision, service-delivery system configuration and hardware, demographics, community planning, and regulation. These are sources and uses of information that are not traditionally exploited by utilities in monopoly markets. New markets will require new information, new ways of using information, and new ways of thinking about information.

Regulatory commissions also will operate in more competitive environments. As utility markets evolve and competition for government funds becomes more intense, regulatory commissions will also need to apply information to the effective provision of 
public service. ${ }^{26}$ Potential applications of information technology that may well serve regulatory commissions may include:

- Analyzing customer complaint data to determine utility service delivery difficulties

- Evaluating infrastructure to assure public safety

- Identifying cross subsidization of utility customers

- Modeling alternative methods of regulation

- Evaluating the effects of mergers, acquisitions, joint ventures, and interlocking directorships

- Identifying core customers (i.e., those customers without competitive alternatives)

- Evaluating the level of risk assumed by utilities in competitive markets

- Assessing the effectiveness of demand-side management (DSM) programs

- Measuring the achievement of social goals and evaluating funding mechanisms for the achievement of social goals

- Measuring the extent of market dominance by a single utility

As indicated by the types of analysis that may be necessary and as regulatory commissions adapt to emerging competition, the types of information they need will also change. New regulatory methods rely less on consideration of internal utility behavior (e.g., executive salaries and the prudence of investments) than on the direct impact of utilities on consumers (i.e., service and price). In an integrated information

${ }^{26}$ Two of the implementation steps identified by state public utility commissioners at the NARUC/NRRI Summit were "Provide more data mechanization and management (e.g., Geographic Information Systems, electronic bulletin boards)" and "Pursue automation, make use of 800 numbers, enhance staff skills and productivity, more to "paperless" commissions." Staff of the National Regulatory Research Institute, Missions, Strategies, and Implementation Steps for State Public Utility Commissions in the Year 2000: Proceedings of the NARUCNRRI Commissioners Summit, 29,31. 
system that pulls together a wide array of data, utility cost information will become less crucial, except where affiliates are involved and cross-subsidization remains a possibility. As competition emerges, market information, ir,cluding market penetration information and pricing information, will become more central to the commission's mission. To date, commissions largely have relied on information provided by the utilities to evaluate the impact of regulatory policy. In their new roles, commissions may require both independent sources of utility information and information about markets and consumers.

Indeed, it is possible that a central role of a regulatory commission may be to insure the free flow of information necessary for competition to flourish. ${ }^{27}$ Standard definitions of purely competitive markets require a large number of independent buyers and sellers, a standard product, free entry and exit of firms, no control over prices, no nonprice competition, and II Is possible that a central role of a regulatory commisston may be to insure the free flow of information necessary for competition to frounsh. perfect information. While no one expects perfect competition to emerge in utility markets, utility customers even in imperfectly competitive markets will need accurate price and quality-of-service information. To the extent that advertising does not accurately transmit price and quality-of-service information, customers will fail to reap the full benefits of competition.

Currently, many consumers cannot make informed decisions because of the lack of information. For bulk purchasers, the financial markets, which operate efficiently because of the free flow of information, provide appropriate price signals. For other

${ }^{27}$ One of the strategies identified by commissioners at the NARUC/NRRI Commissioners Summit was "to ensure timely disclosure of market information." Staff of the National Regulatory Research Institute, Missions, Strategies, and Implementation Steps for State Public Utility Commissions in the Year 2000: Proceedings of the NARUCNRRI Commissioners Summit, 18. 
customers, regulatory commissions may need to assure that price and quality-ofservice signals are clear. ${ }^{28}$

To some extent, regulatory commissions have always been information-based organizations, in that information about utilities has been their stock-in-trade. To become fully information-based, however, commissions will need to find ways to use information to serve the public and to allow the investment in information technologies that decentralize their operations rather than serve existing hierarchies.

Other necessary challenges for regulatory commissions include:

- Interacting with state personnel systems that may not provide the flexibility to reward commission knowledge workers without assigning supervisory duties or titles.

- Broadening the range of commission data sources and ending the reliance on utility-provided, cost-of-service data.

- In an environment of cost-cutting, justifying the expenditures of funds for information systems which may have a limited short-term payoff and for which it is difficult to quantify certain specific benefits.

- Gaining access to important utility information systems (in order to avoid the creation of duplicate systems and gain access to information available only to the utility) under the assertion that information is proprietary; safeguarding proprietary information if access is gained.

- Encouraging utilities to prudently invest in systems that will enhance longterm competitiveness.

- Determining who should pay for utility information systems especially when those systems will provide benefits to unregulated portions of the business or to the utility in future competitive markets

- Identifying the appropriate cost-benefit analyses for information systems for regulated utilities. (See Chapter Three.)

${ }^{28}$ According to the California Public Utilities Commission one of the improvements in consumer access is to "Ensure that consumers have ready access to accurate and understandable information necessary to make informed decisions about utility services in a competitive market." The California Public Utilities Commission, A Report on Our Process for Change: Vision 2000 (San Francisco, CA: California Public Utilities Commission, 1995), III-5. 
- Encouraging the necessary culture shift from old regulatory regimes to the new, more competitive environment by utilities and commissions.

- Identifying the means to ensure the appropriate level of privacy over information about utility customers.

The biggest challenges for commissions will not be to find ways to use information to benefit customers; the opportunities to productively use information are virtually unlimited. The biggest challenges will be funding, implementing, and convincing others that there will be a long-term payoff for information systems and data investments.

According to Tom Peters, "it's easy to get mesmerized by the information technology "thing." And it's dangerous not to."29 As utilities and regulatory commissions implement new information technologies and make the conversion to information-based organizations, they will need to innovate--to significantly alter old patterns of behavior. As they do so, they might consider the following myths about innovation: ${ }^{30}$

1. If it works, don't fix it. Often systems and procedures appear to work when, in fact, there are far better alternatives available. In other cases, the adage about the cactus may apply to organizations and their procedures-it may be dead for a year before it is noticeable.

2. Build a better mousetrap and the world will beat a path to your door. Information technologies, like mousetraps, have to be sold to skeptical buyers. The fact that a sales effort is necessary does not necessarily mean that the idea is a bad one.

3. There is nothing worse than a solution in search of a problem. It is certainly possible to attempt to apply new technologies to old problems to an excessive or dangerous level. In other cases, however, new technologies create new opportunities; there is nothing wrong with

${ }^{29}$ Tom Peters, Liberation Management (New York, NY: Ballantine Books, 1994), 108.

${ }^{30}$ Denos C. Gazis, "The Elements of Innovation," Management of Innovation and Change (Columbus, OH: The Ohio State University College of Business, 1987), 28-30. 
matching new opportunities to real problems.

4. You cannot guide (or manage) innovation. Though innovation is sometimes difficult to manage by traditional methods and can be stunted under heavy-handed management, leaders can map out general directions for exploration and raise critical questions and concerns.

Without question, the types of information systems discussed here and in the remainder of this report are often costly. Further, the radical organizational change that may result from the effort to become an information-based organization will not be easily accomplished. But utilities and regulatory commissions are rapidly being thrown into a brave new world. According to Blake Ives and Sirkka Jarvenpaa, "The greater the environmental turbulence, the greater the need to compete with information and knowledge."131 The application of new information technologies is one tool that can assist in the transformations required to survive in that new world, which undoubtedly will be rife with turbulence.

The next chapter provides a more detailed examination of the challenges inherent in making the transformation to an information-based organization.

${ }^{31}$ Blake Ives and Sirkka L. Jarvenpaa, "Competing with Information; Empowering Knowledge Networks with Information Technology," The Knowledge Economy: The Nature of Information in the 21st Century, 57 



\section{CHAPTER THREE}

\section{TRANSITION TO AN INFORMATION-BASED ORGANIZATION}

Having identified the importance of information for utilities and regulators in the new competitive marketplace, in this chapter we identify some of the steps required to make the transformation to an information-based organization. Here, we also explore some of the information-system requirements for an information-based organization, system planning and development methods, and the evaluation of costs and benefits.

\section{Information System Requirements}

Making the transition from a traditional organization to one in which information is the key commodity requires more than simply investing large amounts of money in information systems, though additional investments will likely be required. It requires investment in the right kinds of information systems.

There are at least seven types of information systems. They include: ${ }^{1}$

- Transaction processing systems--systems that perform daily routine transactions, such as payroll and connection requests.

- Office automation systems--systems, such as word-processing systems and electronic mail systems, that are designed to improve office efficiency.

- Knowledge work systems--systems that assist knowledge workers in the creation and integration of new knowledge.

- Management information systems--systems that help managers plan, control, and make decisions.

${ }^{1}$ Kenneth C. Laudon and Jane P. Laudon, Essentials of Management Information Systems: Organization and Technology, (Englewood Cliffs, NJ: Prentice Hall, Inc., 1995), 34-47. 
- Decision support systems--systems that help managers make semistructured and unstructured decisions by combining data and analytic models.

- Executive support systems--systems that help managers at the executive level make strategic, unstructured decisions through advanced graphics and communications.

- Strategic information systems--systems that address the goals, operations, products, services, or environmental relationships to help the organization gain a competitive advantage. ${ }^{2}$

Most utilities and commissions have established transaction processing systems and office automation systems. Some may have created management information systems. Those systems impact the organization internally and make it more efficient. The challenge for an organization attempting to optimally use information and to achieve a competitive advantage based on that information is to develop systems that make the organization more effective in its interactions with its external environment-particularly knowledge work systems, decision support systems, executive support systems, and strategic information systems. These systems require that different types of information be brought together and maintained as needed. The more data sources, internal and external, that can be brought together the more powerful the system and the greater its ability to find competitive opportunities. For example, the utility marketing manager may want to bring together information about customer demographics, service-delivery infrastructure, and customer billing in order to plan an effective marketing strategy for a new or expanded product.

Effective knowledge-work systems require, in addition to powerful computer hardware: ${ }^{3}$

- Access to external knowledge bases

${ }^{2}$ Systems like GIS, which are both tactical and strategic, can actually address several of these seven types. Given the specific data base content, a GIS can support the last five of these system types.

${ }^{3}$ Laudon and Laudon, Management Information Systems, 355-357. 
- Software containing powerful graphic, analytic, document management, and communication capabilities.

- A user-friendly interface.

The creation of these sophisticated systems poses many challenges for an organization. Cost is certainly one challenge. Data compatibility is another. Links between systems are costly; having insufficient links is costly, too. ${ }^{4}$ One view is that it would be ridiculous to attempt to construct a single, master system that meets the needs of the entire organization; this "total systems view" presumes that someone in the organization can understand all the information needs of the organization. ${ }^{5}$ A more contemporary view is that systems should allow the flow of information from one user to another as the needs of the organization require. ${ }^{6}$ Although significant effort may be required to integrate systems using a common core technology, flexibility is the key to resolving the tension between the creation of a system intended to decentralize decision making and meet the needs of a wide variety of users.

\section{Identifying Information Requirements}

Prior to building information systems, organizations need to attempt to identify their information requirements. In addition, it is difficult to identify the specific requirements of information systems when those systems are intended to radically reshape the organization. For the development of its information system, the Wisconsin Public Service Commission adopted a general vision statement appropriate

\footnotetext{
"Ibid., 57.

${ }^{5}$ Ibid., 46.

${ }^{6}$ Ibid.
} 
for the effective development of systems in uncertain and rapidly changing times. The Wisconsin Commission said that it would provide information: ${ }^{7}$

WE CAN ALL USE in a way that:

- makes information available from as close to the source as possible...

- provides direct links to facilitate exchange of information with Customers within the constraints of security and confidentiality...

- processes information into its most usable form: voice, text, graphics, video image...

- provides information at the appropriate level of detail for different situations and users...

- provides for maximum accessibility of information to all Customers ...

- uses state-of-the-art tools and standardized processes for designing and developing systems...

- develops systems that are flexible and therefore more amenable to change...

- facilitates seamless transfer of information ...

- looks for opportunities to use ready-made software as opposed to developing inhouse...

- harnesses the use of "expert systems" to analyze information ...

- provides the transition to a paper-less environment...

- $\quad$ support QI (Quality Improvement) projects by looking for ways to streamline processes.

${ }^{7}$ Public Service Commission of Wisconsin, Information Technology Strategic Plan: Final Report, (Madison, WI: June 1992 - September 1992), 11. 
There are two principal methods for establishing information requirements: enterprise analysis and critical success factors. ${ }^{8}$

Enterprise analysis is a "bottom-up" approach. It begins with a survey of managers to determine what information they use, how they gather that information, what their environment is like, what their objectives are, how they make decisions, and what data they need. Groups of data elements are then organized into groups that support related functions. From the groupings, managers can determine where to create information systems that support organizational functions. ${ }^{9}$

Enterprise analysis creates a detailed picture of the information needs of the organization and is particularly well-suited to new organizations or those that have never analyzed their data needs. It produces volumes of data that may provide a unique look at the way an organization generates and uses data. That data is, however, expensive to collect and often difficult to analyze. Enterprise analysis also tends to focus on existing information needs and uses, and thereby tends to automate existing functions. ${ }^{10}$ As such, it better serves Total Quality Management (TQM) than reengineering. Enterprise analysis may be appropriate, however, for utilities and regulatory commissions as they attempt to create information systems that support new, unfamiliar environments with entirely new data needs. Enterprise analysis may also help utilities and commissions integrate isolated information systems and create enterprise-wide systems.

An alternative to enterprise analysis is the use of critical success factors (CSFs). The CSF method is based on the hypothesis that the information requirements of an organization are driven by a small number of success factors identified by managers. If those CSFs can be met, the organization will be more successful. ${ }^{11}$

\footnotetext{
${ }^{8}$ Laudon and Laudon, Management information Systems, 256.

9 lbid., 257.

${ }^{10}$ Ibid., 257-258.

11 Ibid., 259.
} 
CSFs are defined by interviewing key managers to identify goals. This results in a smaller set of data than would be gathered through enterprise analysis. That smaller data set is then aggregated to create a picture of the overall firm's CSFs. Information systems are created to serve those CSFs. ${ }^{12}$ For example, if a manager is concerned with maintaining existing customers, a relevant CSF may be quality of service. If quality-of-service is identified as a CSF for the organization (in addition to being a CSF for that particular manager), an information system providing quality-of-service information would be built.

The CSF method can be targeted to the structure of the industry and to particular organizational competitive strategies. ${ }^{13}$ It performs better than the enterprise analysis method in developing systems to serve top managers and in identifying the information needs for decision making and executive management. Because of the limited amount of data involved, however, application of the CSF method is more art than science. ${ }^{14}$ Care must also be taken to insure that the CSF method does not mirror the traditional, task-specific development of information

The key for utilities and regulators to the cost-effective application of information systems is the identification of those business activities wher a competitive advantage can be gained.

systems and to insure that, as

organizations "flatten," information is provided to knowledge workers at all levels of the organization instead of just to top managers.

Irrespective of the method chosen, the key for utilities and regulators to the costeffective application of information systems is the identification of those business activities where a competitive advantage can be gained.

${ }^{12}$ Ibid.

${ }^{13}$ A closely related variant of the CSF method is where the organization uses strategic planning to identify key organizational objectives for information technologies which are interrelated with its objectives for its human resources, competitive, financial, capital resources, and other plans. These information technology objectives then direct the organization's information requirements.

${ }^{14}$ Laudon and Laudon, Management Information Systems, 259. 


\section{Systems Development Strategies}

Once the organization determines its information-system requirements and determines that a favorable cost-benefit ratio exists, the next step is to develop and implement the systems. Several approaches are available for building and installing information systems; they include: $:^{15}$

- Systems life cycle: the traditional division of the process into six sequential and formal stages with a formal division of labor between systems specialists and users ${ }^{16}$

- Prototyping: use of an inexpensive experimental system for demonstration and evaluation

- Application software package: use of pre-written, commercially available software

- End-user development: the development of information systems by users by using "fourth generation" software which can be manipulated without programming expertise

- Outsourcing: contracting system design, applications development, or operations to outside, specialized and expert, vendors.

In recent years, outsourcing has received widespread use as a way to reduce risk and, oddly, "win back control"17 over information-system development. According to Dataquest, Inc., the use of outsourcing for computer operations has doubled since 1989. ${ }^{18}$ Outsourcing is discussed in more detail in Chapter Four.

${ }^{15}$ Ibid., 269-285.

${ }^{16}$ These six stages are systems analysis, systems design, programming, testing, conversion, and production and maintenance. Ibid., 262.

17 Gregory M. Jacobsen as quoted by Catherine Arnst, "The Networked Corporation," Business Week, June 26, 1995, 89.

${ }^{18}$ Dataquest, Inc., as cited in "Outsourced-and Out of Luck," Business Week, July 17, 1995, 60. 


\section{Cost-Benefit Analysis as Applied to GIS}

Financial models within the utility industry are changing rapidly. Driven by competition, deregulation and shareholder concern over profitability, North America's intermediate and larger-sized electric and gas companies are looking at information technology investments with broader levels of interest.

Regulators and the financial

Regulators and the financial community need to be assured that information technology investments: pass the cost-benefit test. community are watching such actions at these companies with equal interest. They may need to be assured that information technology investments pass the cost-benefit test.

Cost-benefit analysis has been applied to GIS and Automated Mapping/Facilities Management (AM/FM) systems since the first commercial project was initiated by Public Service Company of Colorado in the early 1970s. Since then, many of the thousands of analyses completed for such projects have used tools and techniques employed by utilities for other large capital asset investments, especially computer systems. In many cases, utility GIS has not been viewed as mission-critical. Occasionally, some utilities have viewed GIS as a discretionary investment.

Historically, GIS was viewed as being only about maps and records. Today, GIS is more widely thought of as a tool to effectively and safely operate transmission and distribution facilities; assist in major capital asset investment decisions; determine equipment replacement schedules; improve customer service; support a new wave of sales and marketing initiatives; and provide information about competitors, customer trends, economic development activity, and other strategic issues.

Many view the utility industry as gravitating into two groups. The smaller group contains newer, more aggressive management teams that are quickly and decisively responding to market threats and opportunities. The second group is more conservative and slower to act, does business traditionally, and shows less interest in 
future positioning for a fiercely competitive energy environment.

Not surprisingly, these two camps pursue entirely different approaches to costbenefit analyses for information technology investments, and particularly GIS. More conservative utility management teams might require exhaustive cost-benefit analyses, construct slow, cautious implementation schedules, and rely on more conservative return-on-investment models. They also focus on automation of certain historic, manual activities--instead of rethinking and changing them.

More dynamic teams, with their interest in competitive positioning, recognize their success is linked to modern, effective information technology and more readily embrace that technology for bold new, aggressive marketing and sales initiatives.

These utilities recognize that a GIS is a strategic underpinning of competitive customer service, marketing strategies, and improved operations effectiveness. They intend to use GIS to help change they way they will do business in the future. These teams still complete due diligence financial analyses while they also embrace strategic benefitsplanning initiatives, comparative information requirements, thoughts of strategic acquisitions, and tools for more aggressive marketing and sales support.

No perfect, correct, or right cost-benefit model or methodology exists for the utility industry. ${ }^{19}$ In fact, several different cost-benefit models can generally accomplish comparable results if a team of experienced individuals employs those methodologies. However, specialized consulting firms offer widely used customized cost-benefit models developed exclusively for GIS economic analysis, which carry the added advantage of previous commission scrutiny and approvals. The typical cost-benefit methodology is broken down into five components as follows:

- Baseline conditions and measurement

- Strategic implementation plan

- Benefits determination

19 Glenn E. Montgomery, "GIS Cost-Benefit Trends for the Utility Industry: Changing Environments, Industry Practices, and Future Trends," Unpublished White Paper, 1994. 
- Cost-benefit analysis

- Sensitivity analysis and risk assessment (and increasingly, on-going project/system financial/performance monitoring

In the GIS baseline, the project team identifies labor cost by user group, document set, activity or personnel classification of predominately manual map/record/drawing related activities associated with those areas that will be automated or impacted by GIS. Geographically related outside costs and backlog reduction costs are inventoried. The project team identifies utility growth rates; inflation rates; document set problems impacting quality; and other variables that affect creating, seeking, maintaining, verifying and using data. All activities are phased in over a study period, typically fifteen or twenty years in duration. Base year costs are then extrapolated on an annual and cumulative basis to provide a baseline condition. This represents the cost to do business without GIS.

The second phase is the development of a strategic implementation plan. Here management and project team members carefully review needs, opportunities for improvement, work/activity process change, and identify future purchase requirements. This includes hardware, workstations, personal computers, servers, output devices, communications, future cost de-escalation projections, equipment replacement cycles, and so on. External costs, such as consulting fees, internal staffing requirements, software for workstations, and other central processing units, applications and interface costs, hardware and software maintenance, site preparation costs, and project labor training costs or estimates are typically detailed. Plans for applications development, land and facilities conversion, business geographics applications, and the purchase of commercial data sets (and even new satellite imagery) are prepared. The strategic implementation plan results in a detailed purchase schedule and cost estimate, and activities are spread over the project study.

A cost-benefit analysis typically focuses a considerable amount of effort on benefits determination in a third phase. These can range from increased productivity 
and speed to decreasing mapping backlogs, elimination of information quality deterioration problems, controlling the cost of information growth, providing tools for new analytical functions, a variety of cost reduction strategies, cost displacements, and increasingly important cash flow impact and various revenue enhancement or revenue acceleration effects. Benefits include specific labor and productivity improvements, personnel reduction, and quantification of strategic benefits. Increasingly, intangible, but important, corporate, department, or customer benefits are being quantified. This can involve improved response, accuracy, consistency, currency, and completeness, better information available at work locations in the field, improved usability of graphic products, improved communications and coordination associated with geographic data, and other savings.

In the fourth phase, the cost-benefit analysis model adds all costs and benefits projections on an annual basis and provides annual cash flows. Costs are accumulated over the study period to calculate return on investment and net savings. Most frequent economic indicators include internal rates of return which today typically range from ten to forty-five percent or more. Calculations frequently are divided into those with "hard benefits" and those "without hard benefits," which produces more refined evaluation of economic performance and cost recovery. When cost-benefit ratios are used, industry indicators frequently start at 2:1 but target considerably higher ratios. Not infrequently, current utility industry cost-benefit ratios may be several factors above this and internal rates of return may range from thirty to forty percent or more. For the average utility of 500,000 customers such calculations typically create spreadsheet models ranging from 50-120 pages in length (for spreadsheet models only). Detailed write-ups of strategic implementation variables typically range from $30-$ 200 pages; baseline conditions frequently add 100-200+ pages plus appendices. This level of documentation sounds considerable but is actually required by many utility executive teams to complete a thorough investment analysis and provide sufficient documentation for public utility commission review now and retrospective inquiry years into the future. 
The final step in the cost-benefit methodology involves sensitivity analyses and risk assessment models. Sensitivity analysis is performed on system cost, conversion cost estimates, baseline estimates, and productivity factor estimates. Sensitivity analysis provides a method to evaluate implementation cost changes, insight into defining alternatives, high- and low-cost ranges for overall project economics, and input to subsequent risk management assessments.

\section{Comparing Cost-Benefit Results}

Comparing cost-benefit analyses and results between utilities is difficult. After all, a "benefit" at one company may be a "liability" at another; an allowable, tangible quantification at one utility may be eliminated at another as soft or intangible; benefits in one part of the country may be nonexistent in another; regulatory mandates in one state may be of no consequence elsewhere. What's more, with the full-scale shift on from traditional utility rate base analysis toward market-based decision making, comparisons of financial indicators resulting from cost-benefit analyses vary widely among companies.

Typical industry cost breakouts, including hardware/software, data conversion, labor, and so on, for investor-owned electric and gas GIS initiatives of moderate size can be characterized by the pie chart in Figure 3.1. Clearly the big-ticket item is data conversion, which is the task of taking paper-based information, including map and facility graphics, and converting it to computer databases. A relatively smaller percentage of the cost goes to software applications and interface development, which is where most of the tangible benefits can be found in terms of putting systems to work and linking them with other existing computer systems.

An industry overview of how benefits are allocated at a typical electric or gas company can be seen in Figure 3.2. Interestingly, labor savings typically account for only thirty to forty percent of projected benefits over the typical fifteen to twenty year life of a project study. Considerable upside potential will flow from strategic benefits, 


\section{Fig. 3.1 GIS Implementation Costs}

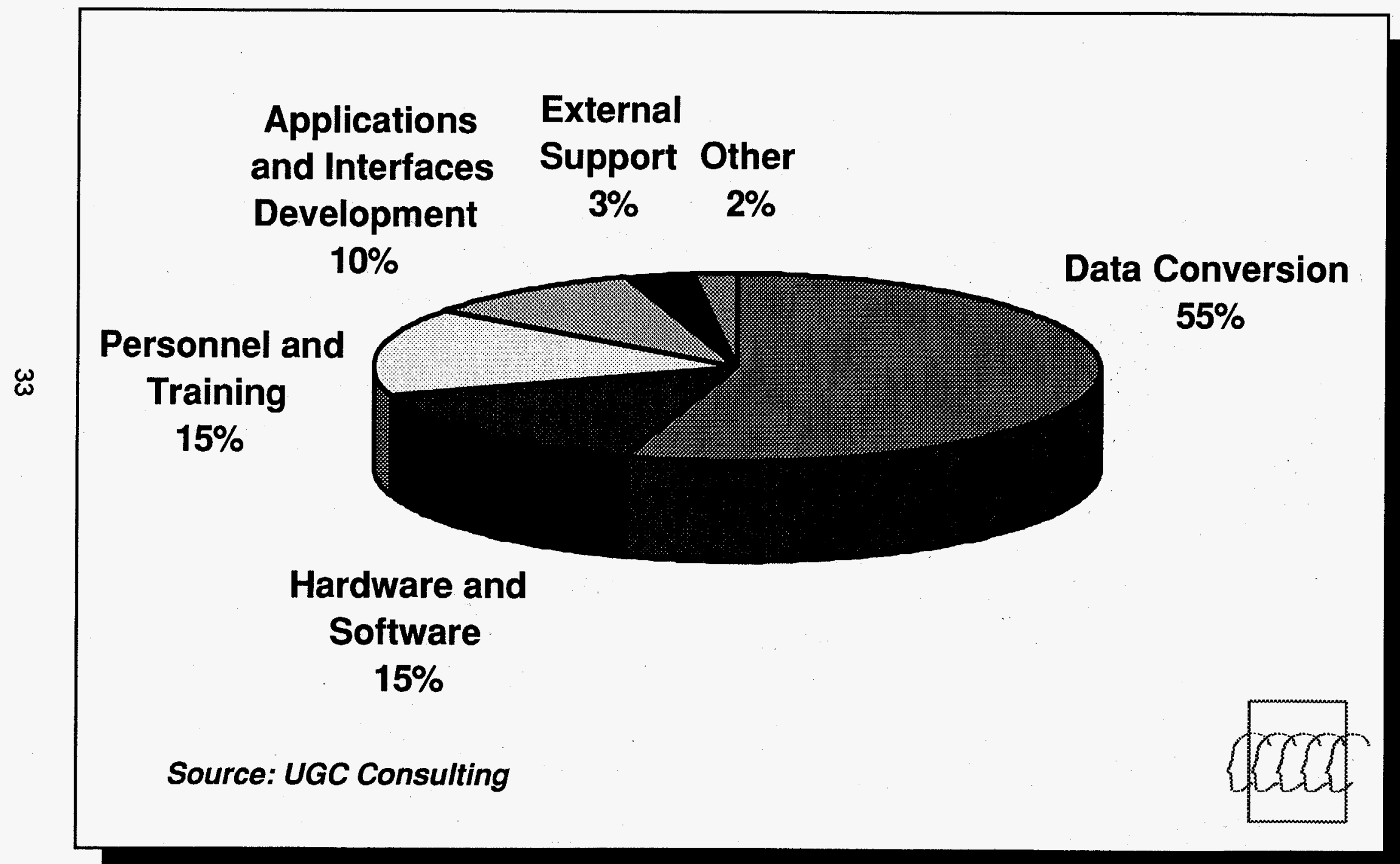




\section{Fig. 3.2 Current Benefits Allocation for Typical Utility Cost-Benefit Study}

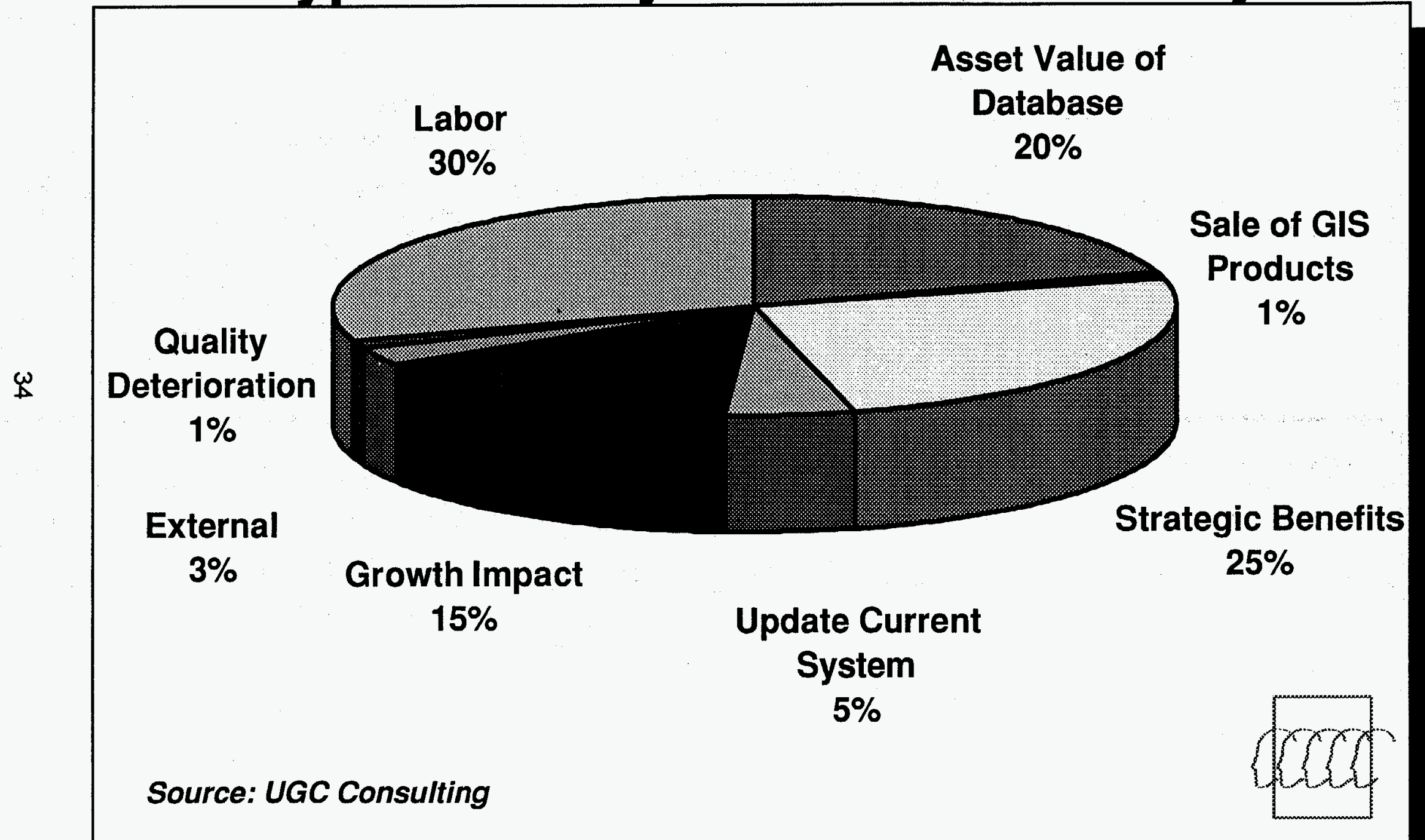


business geographics applications, asset related benefits, the asset value of databases, and issues associated with the cost of growth and change in the utilities. The sale by utilities of GIS products to the marketplace, by contrast, is minuscule and industry trends do not appear to favor that area as a source of cost recapture.

\section{Strategic Benefits-Dynamic Scoring}

One of the most important cost-benefit trends for utility GIS systems is that strategic benefits justify most projects. In many assessments, they literally make the difference in presenting an acceptable project to senior executives. Strategic benefits include attracting or better segmenting new customers based on lifestyles and demographics, developing and supporting new customer-specific programs and services, better understanding a competitor's capabilities, and even providing detail required to support multiple new rate classes, in part based on customer geographic location.

The fast-changing utilities business environment all but ensures that the strategic benefits of a GIS will evolve and increase between the time a project is begun and the time it is fully implemented, which may be anywhere from two to seven years. For example, at one Midwestern utility with GIS implemented for the entire franchise area, most of the benefits being created today were not even quantified in the original cost/benefit analysis. Project managers there benefited from the fact that AM/FM/GIS provides a flexible tool to help stay ahead of change. Besides being flexible, GIS allows users to take a corporate view of technology implementation, not a specific departmental view, for functions such as engineering and planning. As such, AM/FM/GIS can be thought of as an "enabling technology" that helps the corporation achieve its mission-critical goals of customer satisfaction, safe operational performance and profitability more quickly and economically than before. In short, the corporatewide integration of a GIS can present a common database that is available to a wide variety of users, afford single-point updating, avoid capturing data more than once, and 
help improve decision-making accuracy and responsiveness. GIS is now viewed by many executives as a supporting technology which is critical to differentiating a utility's products or services, particularly those related to marketing, sales, customer outage management, and certain demand-side management initiatives.

A wide range of benefits from GIS can be either quantified or identified as intangible benefits depending on the type of cost-benefit analysis being performed. Among the benefits are improved customer service and responsiveness, improved corporate image, improved data management, faster or more uniform responses to regulatory agencies, improved management decision making, integration with other corporate databases, and improved revenue-producing potential.

Increasing emphasis is being placed on post-implementation GIS project audits. The key to measuring change is to measure performance. When performance is not being measured, it can almost certainly be improved, and that is why GIS offers dramatic opportunities to improve several predominately manual labor activities.

In the final analysis, the big operational benefits of GIS, however, are not in reducing labor associated with map and record creation and maintenance activities although labor costs will be typically reduced. Instead, GIS' real financial impact and leverage, like that

The bilg operational benefits of GIS are created through data and application integration. of other knowledge-work systems, is through data and application integration. Customer Information Systems, Trouble Outage Entry/Analysis, Work Management Systems and related operations systems lend themselves to full integration with AM/FM/GIS as a backbone technology. When business geographics applications are added to a GIS, their roughly 6-10 percent increase in overall project cost can boost a project's return on investment to the range of thirty to forty-five percent or more. ${ }^{20}$

${ }^{20}$ UGC Consulting research, 1994. 
Today, roughly nine out of every ten GIS projects require detailed costbenefit analyses. The remaining one requires considerably less formal analysis

Roughly nine out ot every ten GIS Drojects reguire detailed cost benefit analyses:

and enjoys an extraordinarily high level of

support from executive management or has a single specific financial intent that is clear and unquestionably positive. For those projects requiring detailed cost-benefit analysis, the movement is toward "dynamic scoring" and related economic quantification.

\section{Linking GIS with Strategic Direction}

Utility executives evaluate cost-benefit analyses by considering foreseeable cash flows, and then determining how projects relate to other investments over comparable periods of time. To develop a successful cost-benefit analysis focus, one must understand pending utility issues. These include downsizing/right-sizing, decentralization, declining allowed return on earnings, increased competitive pressures, increased cost of capital, and limited incentives for better performance.

In evaluating financial models,

Customer satisfaction will eventually displace regulation as the main tocus in the electric, gas, and local telecommunications industries.

most executives expect that, with emerging competition, customer satisfaction will eventually displace regulation as the main focus in the electric, gas, and local telecommunications industries as has become the case in long-distance telecommunications. Companies unable to effectively satisfy customer needs may no longer be in business.

Utilities are taking steps to improve the success of information technology projects, like GIS, including developing a business assessment of corporate goals, existing systems, and current technologies; developing technical plans and budgets; 
developing a strategic plan that is business-driven and flexible; streamlining traditional analysis and procurement processes; and embracing cost-benefit analysis strategic plans that include business-driven rather than technology-driven strategies. They are emphasizing action and delivery of short-term results, flexibility, and an ability to assimilate new technologies, and a single "architecture" for delivering applications.

\section{Meeting Market Needs}

Another perspective on developing cost-benefit analyses for information technologies is to understand the benefits to customers, regulators, and the utility itself. These benefit areas cover the following broad initiatives.

Customers want ...

- More responsive service

- Uninterruptible service

- Product differentiation and customized services

- New service options such as power quality systems

- Assurance of well-managed, safe and affordable utility services Regulators want ...

- Access to broader, more timely utility information

- Ability to use more, lower cost, and comprehensive "what if" scenarios

- Improved accountability, where appropriate

- Improved analytical capability for managing regulated programs

- Customers to be satisfied with open choices 
Utilities want ...

- Improved ability to contain costs

- Ability to enhance revenue

- Improved quality levels of service delivery

- Competitive advantage

- Improved strategic decision support capabilities

- Asset optimization

- Improved network analysis capabilities

- Safer system operations

In sum, cost-benefit analyses by utilities and commissions for information systems like AM/FM/GIS projects quantify tangible costs and benefits, identify intangible costs and benefits, and codify technical and economic viability and a project's return on investment. The strategic and financial benefits of these projects-namely, integration of corporate data, improved information access, reduced labor and asset costs, new tools for certain forms of revenue enhancement or acceleration, improved marketing capabilities, improved customer responsiveness, and better decision-making capabilities--are emerging as the dynamic, driving forces behind funding approval and implementation success. In today's fiscal environment, virtually no GIS project leaves the ground or is sustained without significant analysis provided by such a cost-benefit methodology. Many utilities also find that effective, focused GIS cost-benefit models actually contain significant content and basis for subsequent project risk identification, mitigation, and management. 


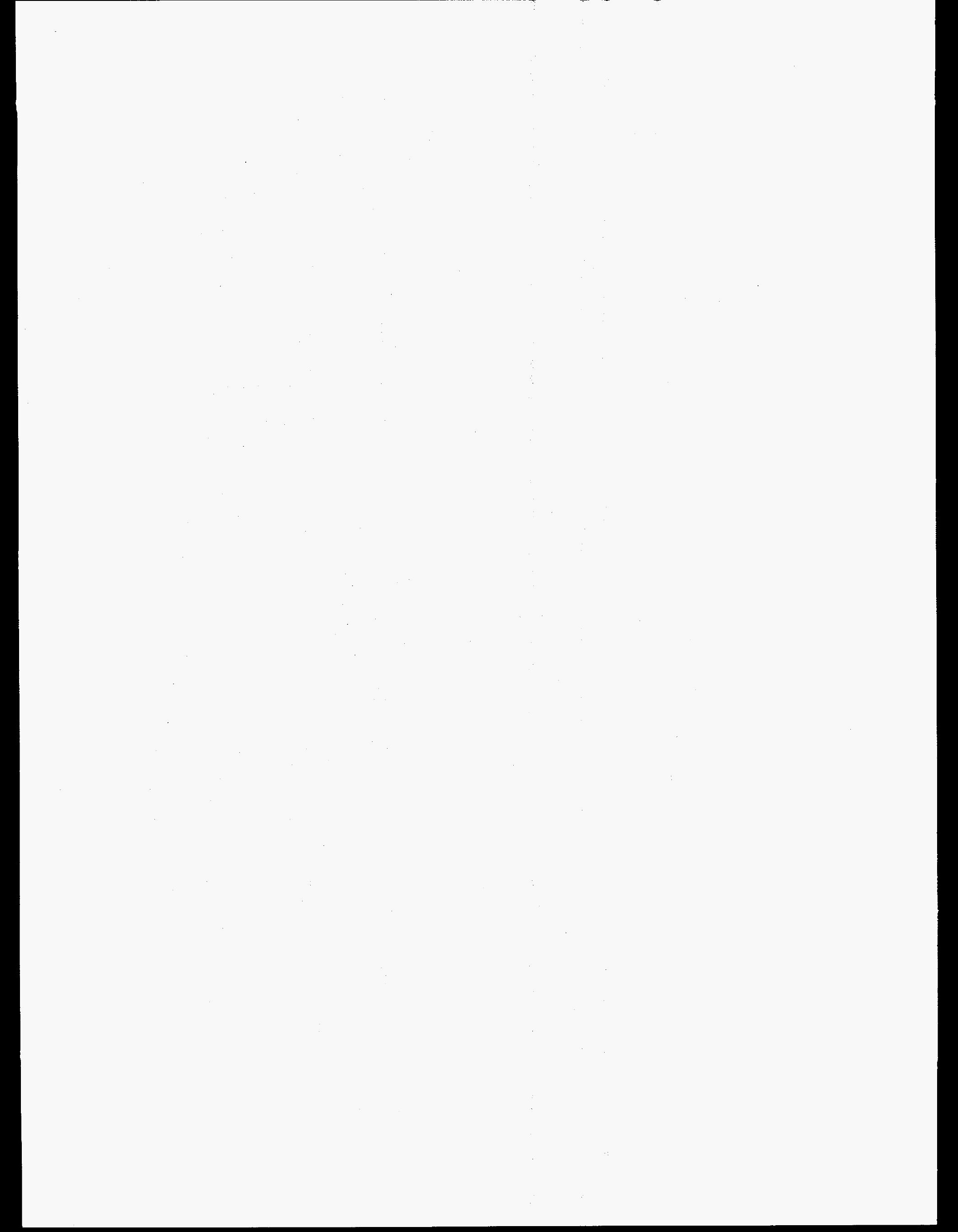




\section{CHAPTER FOUR}

\section{THE APPLICATION OF GIS TECHNOLOGY'}

Not surprisingly, many utilities still rely on paper-based record keeping. After all, electric, natural gas, telephone, and water utilities built much of their infrastructure long before computers made automated record keeping imaginable. It should come as no surprise that most utilities have vast store rooms filled with paper maps and records that have been laboriously created and maintained by hand. Indeed, one source suggests that at utility companies, a large percentage of all employees are "information workers" who spend 60-80 percent of their time using, creating and maintaining geographic-related information. ${ }^{2}$

One study examining the steps required to establish new gas or electric service at a combination utility revealed the following: construction drawings were prepared by two different designers and ultimately were not used as part of the permanent records; many facility records were manual and fragmented; gas and electric maps used different landbases, scales, and standards; a several man-year posting backlog of mapping work existed; and the time required to complete the work order life cycle was lengthy. ${ }^{3}$ Experience has shown that this type of scenario remains the rule rather than the exception at the majority of North American utilities though the conversion to GIS is planned by many. As utilities strive to become more competitive, satisfy their customers, and maintain regulatory standards, they are recognizing the need to adopt

${ }^{1}$ The majority of this chapter and the two that follow focuses on the application of GIS to utilities. For the most part, the same principles would also apply to the development and installation of GIS systems by regulatory commissions.

${ }^{2}$ Stephen R. Lougheed, "The Information Utility: A Model to Facilitate Effective Data Sharing," New Directions, New Dimensions, Proceedings of the AMIFM International Conference, XVIII, Baltimore, MD, March 20-23, 1995, 27.

${ }^{3}$ Michael E. Dumsha, "Business Process Reengineering Methods in Design and Justification of a GIS Project," AMFM International Conference XVI Proceedings, March 22-25, 1993, 271. 
appropriate technological tools to help them become more efficient and responsive.

Significant competitive risks and opportunities exist in the utilities industry today. The keys to success in this rapidly changing environment are the ability to retain existing customers, compete effectively to gain new customers, and respond quickly to new opportunities that can enhance revenues.

Tools known as "Automated Mapping/Facilities Management" (AM/FM) and "Geographic Information Systems" (GIS) are two of the computer-based technology tools being adopted by utilities.

GIS first emerged at Harvard University in the late 1960s. A related technology development, known as Automated Mapping and Facilities Management (AM/FM), appeared in the utility industry when Public Service Company of Colorado (PSCo) began conceptualizing and constructing an AM/FM project around 1969.

At that time, data-processing managers at PSCo wanted help in controlling their growing mountain of distribution maps. A project was launched to study the idea of automating the utility's mapping functions, but after several years the utility and its project partner concluded that available computer hardware and software technology were not yet mature enough to economically accommodate the graphics

The compule based systems were. aimed at entiancing engineenting. efficiency and promoting cost containment eftoris boin of vilich were rey concens oluning the early. years ot regulatony prudency $2010 \% 5)$ requirements of utility maps.

Others took up where PSCo left off. This time, however, rather than focusing solely on automating distribution maps, developers studied the distribution facilities themselves with an eye toward solving the problem of maintaining records of facilities and their relationships. The problem to solve, these developers concluded, was related to databases, not graphics.

In short, AM/FM emerged primarily to solve the utility industry's growing need to manage its widely dispersed and incredibly complex array of networked facilities and its 
related need for automated maps. The computer-based systems were aimed at enhancing engineering efficiency and promoting cost-containment efforts (both of which were key concerns during the early years of regulatory prudency reviews). These systems' initial development was driven primarily by engineers, planners, and accountants within the utilities. Not surprisingly, the first solutions were largely graphic and made computerized drafting functions more efficient.

During its infancy, AM/FM technology relied heavily on representing what are called "point" and "linear" functions. In simple terms, these are such things as a utility's poles and conductors, valves and pipes. ${ }^{4}$ Related information, such as conductor voltages and pipe sizes, typically was stored as text in other computer-based graphic files. This arrangement proved of limited usefulness, however, because no database linkage was established between, say, an electric conductor (a linear element) and a corresponding voltage (a graphic element). In other words, the different types of data could not "talk" to one another and could not be easily manipulated. As a result, these systems added little to a utility's overall corporate strategy and addressed few if any significant regulatory issues.

The potential uses of AM/FM systems were not lost on utilities, however. For years, utilities manually created a variety of maps in their daily activities. For example, thousands of maps and drawings based on maps typically are required to keep water distribution systems or utility transmission and distribution lines operating safely and efficiently. Telephone companies also use maps, for example, to resolve client assignment record conflicts within large wire centers.

Utilities also use large quantities of "location-specific" information that can be related to a map. Such information usually comes in the form of a nongraphic record or graphical sketch. Utility maintenance information and equipment records such as pole cards are examples. Not surprisingly, the sheer volume of information created, 1993).

\footnotetext{
‘ Glenn E. Montgomery, GIS Data Conversion Handbook, (Fort Collins, CO: GIS World Books,
} 
accessed and maintained by and for utility company users is overwhelming. A typical utility over the course of its existence may amass several million pieces of geographically referenced paper.

At one Regional Bell Operating Company, a study revealed that customer addresses were recorded at least sixty different ways. ${ }^{5}$ The author reports, "Needless to say, the information is grossly inconsistent. Although each of the sixty copies of the information are apparently adequate for each application, it is impossible to determine which is correct, or 'most' correct, for corporate use."16

All of this paper must be stored, maintained, retrieved and used by many different people in different departments and locations as part of doing business on a day-to-day basis. Distributing this information, often original copies, increases the probability that the information will be damaged, incorrectly altered, or lost. Because

Because the olfitcilles assochteo

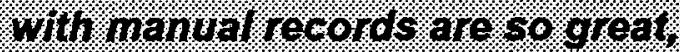
one solition frequently $10100 \mathrm{seo}$ 's 10. restifct access s to these recorobs.

the difficulties associated with manual records are so great, one solution frequently imposed is to restrict access to these records. This "solution" usually has negative implications since limiting access to records also limits their usefulness, or at a minimum their timely use, to the corporation.

Since the advent of AM/FM in the 1970s, many utilities have moved away from exclusively paper-based operations and have begun placing geographic-related record-type information into what are known as "tabular digital databases," which store a tremendous amount of text information. But only recently have they begun to modify these databases to add geographic-related "match keys" or database "links" that allow computer software to relate information in these databases to information in graphic databases and back again. In other words, linkages are only now being built to let

\footnotetext{
${ }^{5}$ William R. Donaldson, "Enterprise Data: Fact or Fiction, or, How to Stop Worrying and Accept the Conversion Cost," AMFM International Conference XVI Proceedings, 295.

${ }^{6}$ Ibid.
} 
utilities access both information about a specific piece of equipment or infrastructure as well as its physical location. The ability to relate both types of information is of profound importance in enabling a utility to improve its efficiency and effectiveness. As a result, it is becoming increasingly practical and economically feasible to utilize GIS Iinkagess are only now being buthl to let utilities access both intormation about a spectiflc plecce or equipment or infrastructiro as well as its. phisicallocation. technology to help create, maintain, manage and use maps and geographic-related records simultaneously.

This change in focus has broadened the usefulness of GIS among utility companies, elevating the strategic importance of these computer-based tools for a variety of corporate-wide initiatives. Some of these initiatives will be described later in this report.

To further familiarize the reader with the differences among and characteristics of these basic technologies, the remainder of the chapter describes the following frequently used acronyms CAD, CADD, DBMS, AM/FM and GIS and outlines these systems' uses by utilities in each utility sector. ${ }^{7}$

\section{Computer-Aided Drafting and Design (CADD or CAD)}

The first commercially feasible applications based on graphic databases in the utility industry were developed to support a variety of design and drafting tasks, such as designing and drawing mechanical parts. This led to the general acceptance of computer-aided drafting (CAD) and related computer-aided drafting and design (CADD) systems. These systems use geometry-based computer graphics technology to automate what had been manual drafting and design techniques required in engineering and technical drawing.

\footnotetext{
${ }^{7}$ The remainder of the chapter is based on Glenn Montgomery, GIS Data Conversion Handbook.
} 
Because they are easy to use and functionally are similar to manual design and drafting techniques of the past, CAD systems have been widely adopted during the past fifteen years. Virtually every architectural, engineering, manufacturing, surveying, and civil engineering firm in the United States uses some form of CAD. Many of these firms' clients, including utilities, now require drawings, plans, maps, and other drafted documents to be produced and delivered in CAD formats. This is because design changes can easily be made and new drawings can quickly be produced. In the utility environment, CAD systems are used primarily at the plant level, where engineers use them, for example, to design mechanical parts. Low-end, low-cost CAD systems today are extensively used throughout the utility industry.

\section{Database Management Systems (DBMS)}

Database Management Systems (DBMS) allow digital tabular data (or text files) to be manipulated. Utilities, for example, maintain databases that contain customer names, addresses, and account data.

A tabular database and access to it are controlled through software and a database design that collectively is called a Database Management System (DBMS). This means that the database contains user data as well as a database design (schema) that the user has to create. Designs typically include the names of data "fields" (attributes) such as "phone number" or "address"; the data format attributes, such as "real," "integer," or "date"; the relationships/linkages between data, such as relating a client name with a phone number; and the grouping of data, such as placing all information for a single client into one record. The user thus actually designs the schema in a process that must be completed before any data can be placed into the database and before the DBMS can support a utility's applications.

Early DBMS solutions typically connected one piece of information to another in a roughly treelike structure. These were called "hierarchical" databases and offered a solution that proved fairly successful in a broad range of data processing applications, 
including some GIS and AM/FM implementations. Their principal drawback was the difficulty users had relating information from one branch to another. In other words, data access was limited in this tree-like configuration and users could not extract related information easily unless it happened to be stored on the same branch as a result of the database design.

This limitation was overcome with the development of "relational" DBMS, or RDBMS. RDBMS are highly flexible and typically allow tables to be joined to create new relations.

Because of its flexibility, the most popular DBMS in use today among utilities is RDBMS. Major drawbacks associated with relational database architectures, storage space requirements, and lengthy display times were largely solved by technological advances.

The use of database management systems by utilities has dramatically increased in recent years. Many DBMS applications were developed to manage information including maps and geographic records. However, DBMS

The uso ol ortabose nanogenent systems oy utitities has oramatically increased in recent years: technology is still generally thought of as a tool to manage tabular data. In the future, databases used by utilities are certain to have a geographic component or layer.

\section{Automated Mapping (AM)}

Automated mapping technology is similar to $C A D$ in that it uses computer graphics technology to produce maps. Automated mapping often uses certain CADtype functions for "digitizing" maps (that is, using a tracing device to convert a manual map to digital form) and for editing. Unlike CAD, however, automated mapping usually does not offer a comprehensive set of engineering design functions. It does, however, offer strong graphic capabilities for preparing high-quality-even cartographic-quality-- 
maps. AM systems keep maps and associated information in digital form, which means that all cataloging, indexing, and organizational capabilities of electronic automation and software can be used to manage the production and maintenance of the maps and data.

Automated mapping has been readily accepted by utilities for several important reasons. First, its central graphic database can easily produce maps of varying content, format, and scales as necessary for all users. Problems caused by lost or misplaced original maps (which happens often in a paper-based environment) are eliminated. Second, an AM system allows digital maps to be more easily updated as changes occur. This eliminates the lag typically caused by having to wait for enough changes to accumulate to justify manual redrafting. Through AM, map maintenance can be less expensive and done in a more timely manner.

\section{Facilities Management (FM)}

All utilities own and operate a large number of geographically dispersed facilities. These include electric lines, gas lines, sewer lines, telephone cables, and/or water mains, all of which must be efficiently planned, designed, constructed, operated, maintained, and managed. Specialized automated systems have been developed to help utilities manage their facilities. These Facilities Management (FM) systems commonly utilize DBMS technology to allow users to query information on facility installation, maintenance, type, capacity, manufacturer/supplier, and so on.

FM systems were created to manage the cards and records that formerly were entered into a alpha-numeric database. Occasionally, this information was crossreferenced with paper maps via the use of "match keys." A match key is a unique piece of datum that is common to the FM database and to the paper or digital map. Examples of match keys include a geo-coordinate reference, structure numbers (such as pole and manhole numbers), street addresses, and equipment or device numbers (such as valve and switch numbers). Several specialized applications were developed 
to run in conjunction with FM databases, such as work estimating, billing for materials generation, and infrastructure audits.

\section{Automated Mapping/Facilities Management (AM/FM)}

Automated Mapping/Facilities Management (AM/FM) systems combine both automated mapping and facilities management database functionalities to create, store, retrieve, manipulate, and display a variety of land base and facilities information. These systems combine facility location information (AM) with facility record information (FM) and provide general land base information. The concept of layered information that CAD offers is used in an AM/FM system; here each successive layer represents a different set of map information. For example, one layer may show the street network; another layer may show city boundaries; and another layer may show the electric, natural gas, or telephone network. Also, spatial relationships may be stored to analyze flows of water, electricity, communications exchanges, and/or gas between points in a network or to analyze overall network conditions.

AM/FM systems have strong linear/network graphic capabilities. Because they were originally developed by the CAD industry, many engineering and design software programs are available to enhance them. The FM component of an AM/FM system means that facilities information database design is an important and necessary step before the combined system can be constructed and used. Indeed, the database must be designed to model the real-world environment it is intended to represent. Its structure also must accommodate the type of data it is intended to hold and the type of applications it is intended to support. This database design requirement makes an AM/FM system more complex and more difficult to implement than either a CAD or an AM system. 


\section{Geographic Information Systems (GIS)}

Like an AM/FM system, a Geographic Information System (GIS) uses automated mapping and DBMS or RDBMS technology to relate data to digital maps and to allow for the creation, storage, maintenance, retrieval, analysis, and display of a wide variety of geographic and tabular information. As in an AM/FM system, "layers" of map or unique data set information can be stored and accessed for analysis and display.

While a GIS is similar to an AM/FM system, its origins as an area analysis tool means that GIS has strong and specialized capabilities that support automated analyses between map polygons of interest. Typical GIS functions require spatial relationships to be stored among specific map features during the database design. These spatial relationships are similar to those required in AM/FM systems, but include features representing areas as well. These relationships are known as "topological relationships", or collectively as "topology." The implementation of topology or other information linkages in a database serves to give additional intelligence to the database.

As with the AM/FM system, database design is an essential step before data can be placed into a GIS and before the GIS can be used. The need to define the database structure so that topological area relationships are correctly modeled

Database design is an essential step before data can be placed into a GIS and before the GIS can be used: suggests that the setup of a GIS could be more difficult to achieve than the setup of an AM/FM system; however, since both types are beginning to provide similar capabilities, differences are quickly diminishing. In addition, some system vendors are providing menu-driven database design modules that greatly reduce the effort needed to perform this task. 


\section{GIS Applied to Regulatory Commissions}

Regulatory commissions have made use of GIS systems. According to a staff member at the Ohio Public Utilities Commission, which began constructing its GIS in the mid-80s: ${ }^{8}$

Rate cases offer an excellent opportunity for applications of GIS technology. The several technologies...can be integrated for the systemwide analysis of a utility for prudency and justification of a rate adjustment. Inventory of facilities, management, customer distribution, property taxes, and emergency preparedness are only a few of the advantages GIS technology offers to Commission staff when analyzing a utility. Combined with background data such as highway, railroads, and boundaries; the Commission staff will have rapid access to a full investigation of any utility. Intimidating stacks of paper become a simple display on a map for ready review and inventory. The rate case process would not only be expedited but would be more thorough and complete.

\section{GIS Applied to Electric and Gas Utilities}

Electric and gas utilities were among the first users of AM/FM/GIS technology, adopting it to automate the storage and retrieval of detailed maps and records associated with transmission and distribution facilities. Many utilities that installed a GIS in the late 1970s and 1980s are now updating their GIS to take advantage of technological innovations and new software applications.

Typical electric utility applications include system planning, load flow analysis, transmission line routing, vegetation management, map maintenance, customer account analysis, asset analysis, work order preparation, underground facilities location, regulatory commission reporting, facilities inventory, and facilities

\footnotetext{
${ }^{8}$ Gene O. Johnson and Richard J. Miller, "Global Positioning: Getting Utility Facilities Down to Earth," The Proceedings of the Ninth Biennial Regulatory Information Conference: Volume II (Columbus, Ohio: The National Regulatory Research Institute, 1994), 130-131.
} 
management. As part of the modernization process, links also are being built to integrate GIS with Work Management, Trouble Outage Entry/Analysis, Customer Information, and related business process systems to create truly enterprise-wide information technology strategies.

The GIS data needs of gas utility companies relate to the location and maintenance of gas transmission and distribution facilities. Gas utilities generally require data with high positional accuracy. Gas utilities are using GIS technology as a tool for network analysis, pipe repair/replacement, decision support, safety leak surveys, and regulatory reporting. Here too, interfaces are being built to link GIS to other business process systems.

Indeed, the recent trend has been for GIS projects to expand in size and complexity as GIS is used to create corporate-wide information technology solutions capable of supporting strategic planning and competitive initiatives. As part of this trend, many electric and gas utilities now expect GIS to be applied more aggressively than ever before to help them meet corporate reengineering needs. This is because the easy exchange of information among departments is more important as utilities streamline operations and eliminate redundancies in capturing and storing data. Together, these forces have changed the context for GIS implementation, creating demand for:

- GIS strategic and implementation plans that are more far-reaching and complex than a few years ago

- GIS systems designed to integrate a broad range of information technology components

- A more extensive range of end-user applications

- Personnel skilled in developing these applications 


\section{GIS Applied to Telecommunications Companies}

With competition in the telecommunications industry now more than a decade old, speed is now the watchword. Easy, fast access to information virtually defines success or failure in emerging telephony, data communications, entertainment, and information access markets. Competition's front lines lie in the area of service provisioning and in related Outside Plant (OSP) activities. It is here that the ability to meet customer needs and to develop new markets depends upon speed, accuracy, and timeliness.

As a result, many telephone companies are reengineering the work processes related to their OSP activities. Specific OSP automation activities are focusing on enhancing the work environment, providing complete and timely enterprise data access for decision making, and replacing paper-intensive and redundant processes. All of this is being done with an eye toward saving time. GIS directed toward a telecommunication company's OSP functions is increasingly looked upon to systematically integrate data and technology to enhance and improve the planning, engineering, construction, and provisioning process.

In general, telecommunications firms require GIS data covering large geographic areas to assist them in managing their facilities and wire centers. Multiple map scales are utilized to map the service areas economically. General GIS applications for telephone companies include planning, design, construction, and maintenance. The ability to trace a wire pair throughout a wire center is one of the desired applications. Another important application is the ability to automatically update a complete database when a wire pair is reallocated (called "cable ripple"). Inventory management, transmission analysis, and work order management applications are also important. 


\section{Business Geographics Applications}

As competition intensifies, utilities of every type are looking for ways to better understand their marketplace, their customer, and themselves. Specialized applications known as "business geographics" can help a utility achieve these goals. Business geographics is defined as applying technology that combines geographic data with geographic analysis to enhance business processes. ${ }^{9}$ Business geographics applications can; for example, help a utility pinpoint new commercial, industrial, or residential growth in its service territory; target customers based on demographic or census data for marketing initiatives and special incentives; and better prioritize capital improvements to respond to customer demands.

Business geographics applications enhance a GIS by drawing on a rapidly expanding variety of commercially available databases that provide demographic data and economic development information along with a myriad of other data types, including customer- or household-specific data. This information may be used, for example, in comparing residential building permit activity to the location of existing electric distribution facilities. This can help suggest where new capital investments need to be made. As competition intensifies, utilities also may use business geographics applications to evaluate their own service adequacy, compare information about their competitors' capabilities, evaluate their customers' business, and model a variety of "what if" scenarios.

Business geographics can be used for a variety of other applications, including the following:

- A gas utility could use commercially available data about its customers' income levels, new car purchases, and driving habits to help locate future natural gas vehicle fueling stations.

\footnotetext{
9 Purvi Rajani, Geographic Technology Markets (Fort Collins, CO: GIS World, Inc., 1995), 1.
} 
- A gas utility could plot the location of competing pipelines in relation to its largest fuel choice customers, helping it formulate strategies to protect key accounts.

- A gas or electric utility could use demographic and lifestyle data to mount competitive and focused appliance conversion programs.

- A gas, communications, or electric utility could use sophisticated customer-based information to identify, sort, and manage highly targeted sales programs that rely on direct mail marketing. Indeed, both AT\&T and $\mathrm{MCl}$ currently use micromarketing techniques based in business geographics applications to compete for lucrative international calling markets and frequent business travelers. ${ }^{10}$

\section{Future GIS Development}

Exhibit 4.1 details some of the likely, future developments in GIS technologies.

${ }^{10}$ Raul Katz, Robert G. Docters, and Carolina Junqueira, "Strangers in Their Own Land," Telephony, July 31, 1995, 18. 
Exhibit 4.1

\section{THE FUTURE OF GIS: AN OVERVIEW}

\begin{tabular}{|c|c|}
\hline $\begin{array}{l}\text { Rej" } \\
\text { reatures }\end{array}$ & $\begin{array}{l}\text { - complete integration with other business systems } \\
\text { - integration of all geographic-related data } \\
\text { - satellite imagery with near real-time updating } \\
\text { - ability to relate specific customers and data to the } \\
\text { infrastructure } \\
\text { - reliance on "shrink-wrapped" software } \\
\text { - ready transfer of data across technologies }\end{array}$ \\
\hline Apolleations & $\begin{array}{l}\text { - marketing: customer selection, de-selection and generation } \\
\text { of revenue models } \\
\text { - real-time customer information } \\
\text { - optimized work management } \\
\text { - automatic dispatch of crews } \\
\text { - land and parcel data management } \\
\text { - enhanced reporting by utilities to regulatory authorities } \\
\text { - ability for regulators to model complex "what-if" scenarios }\end{array}$ \\
\hline $\begin{array}{l}\text { Principal } \\
\text { Data Sets }\end{array}$ & $\begin{array}{l}\text { - current and historic facilities data } \\
\text { - digital orthophotography } \\
\text { - current and prospective customer data } \\
\text { - census data } \\
\text { - competitive facilities and infrastructure } \\
\text { - commercially available business geographics } \\
\text { - municipal, state, and federal geo-data }\end{array}$ \\
\hline $\begin{array}{l}\text { Principal } \\
\text { Users }\end{array}$ & $\begin{array}{l}\text { - "classic" users - mapping and records personnel } \\
\text { - "new age" users - business analysts, engineers, marketers, } \\
\text { planners } \\
\text { - regulatory authorities } \\
\text { - available to all employees }\end{array}$ \\
\hline Methodology & $\begin{array}{l}\text { - parallel implementation -- to allow benefits as datasets are } \\
\text { created } \\
\text { - accelerated applications development }\end{array}$ \\
\hline $\begin{array}{l}\text { Economic } \\
\text { Impact }\end{array}$ & $\begin{array}{l}\text { - lower operating costs } \\
\text { - identification of "preferred" customers } \\
\text { - opportunity to enhance revenues } \\
\text { - opportunity to develop new markets } \\
\end{array}$ \\
\hline
\end{tabular}

Source: Authors' construct 


\section{CHAPTER FIVE}

\section{UTILITY GIS INVESTMENTS: KEY BUSINESS AND REGULATORY DRIVERS}

Significant competitive risks and opportunities exist in the utilities industry today. The keys to success in this rapidly changing environment are the ability to retain existing customers, compete effectively to gain new customers, and respond quickly to new opportunities that can enhance revenues. Among the key trends driving the need and specific planning for GIS $^{1}$ as a technological tool to help utilities meet their objectives are:
- Downsizing
- Outsourcing
- Safety/Regulatory compliance issues
- Environmental impacts and siting
- New competition and competitive alternatives
- Deregulation
- Reengineering

All of these are impacting utilities and need to be considered in strategic implementation planning and cost-benefit analysis for GIS implementation. The first six trends are examined in this chapter. Reengineering is examined in Chapter Six. GIS.

${ }^{1}$ Through the balance of this report, these collective AMFM/GIS technologies will be referred to as 


\section{Downsizing}

One would be hard-pressed to find a utility that does not include "downsizing" or "right sizing" as a key business objective or that has not already conducted significant downsizing. Virtually every utility's business reality encompasses a need to do more with fewer people and at reduced costs. The need to downsize to improve corporate profitability is pushing the purchase of information technologies like GIS, among other technologies. These technologies can improve productivity and should lead to reductions in the number of new personnel that need to be hired and to reductions in existing personnel through attrition or reassignment.

Today, GIS cost-benefit studies and strategic plans, therefore, place emphasis on the technology's capacity to realize savings through reductions in personnel and overtime costs, and elimination or reduction of planned expenditures that are no longer required. Increased emphasis is also placed on the technology's capacity to increase revenue through market growth (product and service) and to reduce planned capital expenditures through better asset utilization.

Downsizing has several additional important effects on GIS planning.

- Downsizing may affect cost-benefit measurements. For example, if the downsizing has led to a decision not to update map records, any related GIS benefits must be compared to estimated costs for doing that work manually.

- Because cost-cutting is a major initiative, internal competition has intensified for project funding. GIS procurements must compete as never before against such technologies as work management systems, customer information system enhancements, supervisory control and data acquisition systems, trouble outage management systems, and so on. The business case analysis for GIS must, therefore, stress return on investment and the strategic benefits gained through system implementation. Similarly, quantifiable benefits must appear to be feasible early in the project life cycle. A winning strategy may be to look for ways to integrate all of these systems. This not only expands the base of support for the overall investment in technology, but ensures that the investment is leveraged as much as possible. 
- Although companies are reducing personnel requirements through downsizing, the size and scope of GIS projects are not diminishing. To the contrary, projects actually are increasing in scope due to a growing emphasis on implementations that cross more than one department or function. At the same time, there are fewer full-time project personnel available at utilities today than there were just a few years ago. Today, companies may be able to devote only a project manager--who is often allocated only part-time to a GIS project--plus resources for internal data preparation and applications coordination; a sharp contrast to the fullydedicated project teams of the past. As a result, companies increasingly must look outside for the resources needed to plan and implement GIS technology. Many are outsourcing information technology projects, including GIS. The economics of outsourcing and its impact on project planning have increasingly positive ramifications in cost-benefit analysis and strategic implementation, as discussed below.

- Reduced human resource levels, prior to GIS implementation, decrease the level of "hard" benefits attributable to employee reductions. An alternative approach for project justification is to say that GIS will preclude hiring additional personnel in the future to maintain the current manual system. This cost-avoidance technique is permitted by some utilities while disallowed by others.

\section{Outsourcing}

In an environment where departmental automation projects are being replaced with streamlined, enterprise-wide information technology efforts, a strong need exists for a new business model for planning, funding, implementing, and managing GIS. Under the old model, the utility company typically hires a consultant, buys equipment, hires a data conversion contractor to create the computer-based data bases from existing paper records, manages the development of software applications that allow the system to perform a variety of utility business needs, occasionally selects a systems integrator to link two or more systems, and, perhaps most important of all, manages the project. Inherent in this model, the utility is responsible for pulling the 
pieces together, for negotiating with numerous contractors and for bearing the risk of implementing the new technologies (usually without the experience of having done it before).

Today's larger, more encompassing implementations have made implementation even more difficult. This is particularly true in light of the downsizing initiatives described earlier, increased regulatory and investor scrutiny of project To.ray s larget moro encompassing Inotementations have made

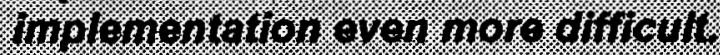
investments and the return on those investments, the greater focus on risk management and mitigation, and the imperative to specialize as a utility service provider rather than act as a generalist.

As a result, an increasing number of organizations are outsourcing information technology projects like GIS. ${ }^{2}$ In these scenarios, project planning and implementation are contracted to third-party systems integrators who accept responsibility for delivering a functional solution, including data, hardware, software, and applications. They commit to delivering a product by a deadline, within budget, and with the expected return-on-investment. At the same time, these third-party entities seek to partner with the utility and carry a substantial portion of the project risk, allowing the utility to focus more directly on its core business.

This model of doing business imposes several demands on GIS project planning. First, such a strategy typically shifts the project risk. The outsource contractor becomes the party contractually accountable for implementing effective solutions and often for accepting both financial and technical responsibility for project success. This removes much of the project management burden from the utility and places it on an expert contractor.

\footnotetext{
${ }^{2}$ Outsourcing implies that the entire business function is shifted to a third-party service provider. CoSourcing ${ }^{\text {sw }}$ is a variant of outsourcing, which implies a collaboration between a third-party service provider and the host company drawing on the strengths and expertise of each to achieve a goal that is greater than what could have been done alone. CoSourcing ${ }^{S M}$ is a registered service mark of the EDS Company.
} 
Second, while the functional needs of various utility end-users remain basically the same, the way in which the technological tools are implemented will change. Specifically, the more competitive marketplace has heightened the need to realize benefits through GIS applications that can achieve rapid payback.

Third, the cost-benefit picture is quite different because outsourcing often involves a financial investment on the part of the contractor. Other financial options include a participatory scenario where the contractor provides the capital investment during the project definition, conversion, integration and implementation phases in return for a share of the benefits derived as a result of the project and enhanced business processes.

Fourth, outsourcing can be a less expensive alternative to traditional forms of internal management. This obviously can improve the cost-benefit results.

Outsourcing also can reduce the amount of time required for system implementation because the contractor is often able to devote a greater number of personnel to the project and can circumvent certain project "ramping-up" and training requirements.

\section{Safety and Regulatory Compliance}

Safety issues and compliance with regulatory directives are primary concerns of all utilities. Most utilities expend considerable resources to ensure that their service is provided reliably and safely. Room for improvement always exists, however.

For example, the American Gas Association recently reported that

Lack ot entorcement may be one. reason for the fallute of these laws to curtail the number of hits, but a more iikely reason is the amount of time it takes utilities to accurately 10 cate theit tacilties and communicate that information to excavators. two-thirds of the reported natural gas incidents are caused by outside force damage. ${ }^{3}$

${ }^{3}$ Barry J. Kemble, Speech to the Finance and Technology Committee, National Association of Regulatory Utility Commissions, November, 1994. 
The Association estimated 70,000 hits to natural gas lines occur each year, at a cost of $\$ 150$ million. This continues despite the near-universal adoption of state laws implementing one-call systems, which are designed to prevent operators from excavating illegally, to the detriment of public safety. Lack of enforcement may be one reason for the failure of these laws to curtail the number of hits, but a more likely reason is the amount of time it takes utilities to accurately locate their facilities and communicate that information to excavators. GIS systems greatly improve the accuracy of the information and the timeliness of the response when "requests for locates" arrive at the utility. This should give excavators more incentive to make the call, thereby increasing public safety and enhancing utility service reliability.

At least six key advantages or benefits of a GIS approach tied to one-call services have been identified. ${ }^{4}$ They include: graphic data that helps operators locate proposed excavation sites, the possibility of sharing data among multiple utilities as well as state and local agencies, the ability to associate a wide range of attributes to individual facilities, and the ability of contractors to submit "requests for locates" by street address, latitude/longitude, state plane coordinates or distance and direction from known features.

\section{Environmental Impacts and Siting}

In an age of NIMBY, BANANA, LULU, and NIMTO, ${ }^{5}$ utility planning, design, and siting of facilities are becoming exceedingly difficult. The public is seemingly becoming virtually "facility-averse." Thus, to receive regulatory approval for the design and siting of facilities, the utility is required to demonstrate that its plan is the lesser of perceived evils. Both the impacts and the benefits of facilities can most effectively be

4 Grenville Barnes, Naser Habash, and Adam Chadwick, "The Development of a GIS Capability for "One Call" Utilities Protection Services," AMFM International Conference XIV Proceedings, March 27-29, $1991,739$.

${ }_{5}^{5}$ Not In My Backyard, Build Absolutely Nothing Anywhere Near Anybody, Locally Unwanted Land Use, Not In My Term Of Office (for public officials). 
demonstrated through use of GIS technology. For example, GIS can be used to identify the electric and magnetic footprint of proposed electric transmission lines under different generating levels and configuration and the proximity to residential areas, schools, and other sensitive sites.

\section{Competition}

The dismantling of the Bell system a decade ago not only opened the door for competition but created an environment through which numerous "baby bells" and independent communications companies could invest in cable companies and nonutility related businesses. In a not dissimilar move, natural gas pipelines now may contract for service directly with end-buyers. Likewise, electric companies see their grids opened up on a wholesale basis and face the prospect of seeing their grids opened on a retail basis.

Despite these revolutionary advances, competition, where it exists, is still relatively new and most utilities are still not adequately prepared to exploit market opportunities. Little is known about new energy conversion sales opportunities or what specific appliances or equipment are in use behind each residential meter. Few

Desplte these revolutionan. advances, competition, where It: exists, is still relatively new and nost utitites are still not adequately. prepared to explotl narket oppontuntiles. Whowledge ot who potential new customers aro and Whero they aro located is missing. utilities are able to relate resources such as facilities to customer locations and consumption. Knowledge of who potential new customers are and where they are located is missing. In short, few utilities are armed with the geographic information tools needed to compete, whether by retaining existing customers or gaining new ones. In addition, pricing of services, which is more discrete than cost-of-service average pricing, will be facility and location specific. 
"Unbundled" service pricing will require more discrete analysis of facilities and customer locations.

As a result, many utilities are looking for ways in which information technology like GIS can create a competitive edge by helping retain existing customers, find new residential customers, and look at ways to aggressively expand utility systems to encompass more large industrial plants and commercial customers. Nonregulated business opportunities are also being aggressively pursued.

The need to effectively compete has placed significant new emphasis on improved customer response and on using GIS for marketing applications. It also has placed increased emphasis on the return on investment and on actually achieving an improved competitive posture by implementing these applications. And because GIS typically needs to interact with other systems to meet these objectives, the importance of an integrated approach is increasing.

For example, marketing departments at aggressively competing utilities make heavy use of GIS. When a new customer calls for service, the process often begins in a marketing department. When these personnel have access to GIS, they can instantly tell customers whether or not there is a nearby gas main or electrical line and what it will take to establish service. By integrating GIS with a variety of business geographics applications, utilities can better target prospects and analyze competitors' strategies. Existing databases that contain demographic information can be integrated and are a key part of the marketing effort. Some of the typical applications factored into costbenefit analyses and strategic implementation plans include:

- Facilities availability analysis, which asks, where are existing facilities relative to customers requesting new service, and how quickly can new service be brought on line and at what cost?

- Competitive analysis, which asks, where are existing competitors, what might their strategies be, how can we most effectively compete, and what actions might be most proactive and effective? 
- Target marketing, which seeks to identify which customers are likely to buy appliances and should be targeted for conversion, where potential nonusers of my utility service are, and what is the most effective marketing approach to tap this market?

\section{Deregulation}

The AT\&T divestiture in the telephone industry, the Federal Energy Regulatory Commission's (FERC) Order 636 in the gas industry, and power wheeling/potential future retail wheeling via the Energy Policy Act of 1992 in the electric utility industry have permanently changed the utility business environment. At the same time, many utility companies--particularly those accustomed to being sole-source providers -- are not well-positioned to accommodate these changes. Many utilities are in the midst of redefining their business operations and examining the range of information technology solutions that may be required to support these new modes of operation. With a goal of maintaining their competitive edge, many utilities are publicly committing themselves to providing high-quality customer services. This commitment has, in turn, dictated the need for employees to be not only customer focused but backed by highly efficient operations support and marketing systems. Business process evaluations, reengineering projects, and work management are focusing on the customer first. The more efficient, integrated and flexible a company's information technology systems are, the better it is able to provide high-quality service to its customers; the more effectively it can assess its marketing intelligence; the more quickly important tactical and strategic decisions can be reached; and the more likely it is that existing customers can remain satisfied and new customers can be attracted.

The effects of regulatory reform and deregulation on planning for GIS has been many-fold. First, these issues have emerged as significant business drivers for procuring these systems. Incentive-based regulation has heightened utility interest in finding ways to operate more efficiently and economically. Automation initiatives are a 
key part of most utility strategies to achieve such efficiencies. At the same time, service territories are increasingly opening to competition. As a result, these territories are no longer looked upon as protected franchise areas but as competitive market areas where success and growth depend upon the effective use of information These teritories aro no longer. looked upon as protected franchiso areas but as competitive manket. ar eas where success and growh dependupon the etrective use of intomation iechnologies, sureh as eis. technologies, such as GIS.

Second, regulatory reform and deregulation have underscored the significance of integrating GIS with other key utility corporate information technologies. This integration is being undertaken to improve competitive response through faster access to better customer and facility data, to improve productivity through streamlined operations and the elimination of duplicate data creation and management, and to improve marketing intelligence.

Third, regulatory reform and deregulation have created the need for use of outside business geographics type databases and applications to meet these new business and marketing objectives. Regulatory reform and deregulation have led many utilities to more closely examine return on investment offered by GIS applications. These applications can help utilities attain a more competitive posture because they extend beyond traditional mapping and facilities management functions to encompass applications that integrate GIS systems with other computer-based business systems. Increasingly, these applications also encompass business geographics applications, such as strategic marketing and competitive analysis. Cost-benefit analyses and GIS strategic implementation plans are placing much greater emphasis on the benefits to be gained through GIS applications that help accomplish business objectives such as:

- Serving customer needs through quicker, more accurate information 
- Providing support for developing accurate proposals quickly for potential large industrial customers

- Providing support for emergency situations

- Improving analysis and timely decision-making capabilities

- Improving access, accuracy, timeliness, and availability of information to all user departments

- Improving response and service to new customers

- Improving information interfaces to other information systems, like complaint tracking, work management, customer information, supervisory control and data acquisition (SCADA), and so on

- Improving information provided to marketing departments so that they can perform their jobs more effectively

- Improving plant design, construction prints, and map updating

- Tracking new construction and operation

- Aiding crew dispatching and work planning

Cost-benefit analysis must identify specific "hard," tangible benefits to achieve acceptable returns on investment (ROI) before most utility executive management teams are prepared to approve and proceed with GIS implementation. Intangible and "soft" (unmeasurable and uncertain) increasingly benefits are considered particularly in light of mounting competitive and strategic information requirements. Also, improved labor productivity estimates typically are used only in part for total ROI calculations. In utilities, follow-up benefits measurements are now being planned and must be accomplished in detail. Strategic decisions to proceed with GIS are crucial in today's cost-focused environment but must be supported by favorable ROIs. In addition, very detailed analysis of alternative GIS technical solutions may be conducted to ensure optimum implementation planning results. 



\section{CHAPTER SIX}

\section{THE APPLICATION OF GIS IN SUPPORT OF REENGINEERING}

When utility profitability was more assured and competition was not yet an issue, information technology investments primarily were made to automate existing manual tasks and to integrate a few key databases, such as property accounts. Many organizations bought stand-alone computer systems to mechanize specific business processes. Investment decisions regarding customer information systems, work management systems, GIS, trouble analysis, and real-time operations were typically made independent of one another. As a result, different groups within the utility made separate commitments to the architectures imposed by these systems.

Today, utilities are finding that increased competition requires more profitability, faster and better decisions, and becoming more customer-driven. These needs, which now constitute a mandate for basic survival, are driving many to take a new look at the organization as a whole, along with the processes involved with managing the utility, the flow of information among departments, and even the job descriptions for individual employees. In short, most utilities are opting either to reengineer their overall business or at least focus on the business processes that can benefit most by such an overhaul.

This, in turn, has a strong impact on GIS strategic implementation and project cost analysis. The implementation approach emphasizes the ways in which whole business processes can be improved through the application of technology tools. This often mandates that the processes be completely rethought and redesigned to achieve improvements in cost, quality, service, and speed.

Compatibility in information exchange among departments is becoming increasingly important as utilities seek to eliminate duplicate data storage and to streamline operations. This allows utilities to abandon commitments to system designs that are incompatible with other utility systems and to move to a broadly overarching system when economically feasible. It also allows utilities to stop purchasing systems 
that must be force fit into their work environment and instead adopt the benefits offered by today's more open systems.

Reengineering puts a strong emphasis on integration of GIS with existing computer databases to improve overall facilities information management. This requires that strategic plans, and associated costs, focus on close logical ties to existing automated information systems such as customer information systems, work order tracking and bill of materials, engineering analysis, and other databases containing facility

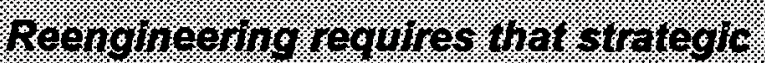

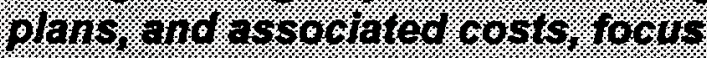

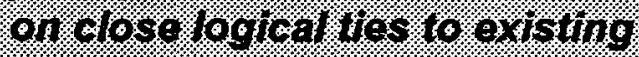

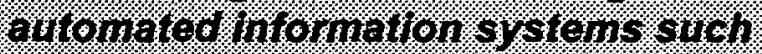

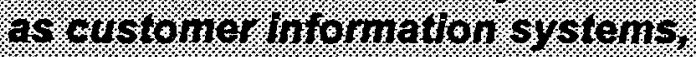

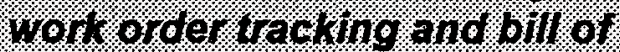
naterals, englneerno analysis. and? othe ratabases contanine factity Wrornation information. Implementing a document imaging or work management system in conjunction with reengineering will also provide additional benefits, which must be analyzed carefully in order to optimize costs and benefits.

To support reengineering efforts, cost-benefit studies not only assess current manual systems, but include evaluation of work, data, and document flows to consider restructuring in the GIS-supported environment. Potential benefits can be more easily determined in this manner. Major improvements are typically available in halting data redundancy, speeding up information flow, increasing integration of databases, and eliminating redundant documents.

From project initiation to system deployment, automation should address not only how a utility does business today but how it will do business in the future. Business process reengineering--defined as radical changes in the way employees do work, use information and make decisions--is taking place or is planned to take place in most companies in North America. Technology such as GIS can enable business process changes in the utility industry by providing a spatial index to information that employees use to make decisions. 
GIS can play a significant role in corporate reengineering efforts under way in the utilities industry, but not if the technology is used merely to automate existing work processes. GIS functionality needs to be fully leveraged to create streamlined work processes that offer corporations a competitive advantage. This section identifies GIS implementation issues related to work process reengineering and provides examples of the role that GIS can play within this environment.

\section{Process Analysis}

Reengineering begins by analyzing a series of steps that constitute a business process. The first step is to identify those who use the product of the process. The dictum typically is to disregard the current process and redesign job descriptions or completely reorganize to allow those who produce and use the output of the information to process the information. In some cases, utilities have established units that do little else but collect and process information.

By focusing on the outcome of processes, formerly labor-intensive "assemblyline" approaches disappear and overall productivity improves. Those directly responsible for certain processes are provided with far greater empowerment, accountability, and "ownership" over the outcome of individual processes, leading

By tooustno on the outcomo o orocesses, fonmens labor hinenswe assembly line taporoanes oisappear ano overall productivit $111010190 \%$ employees to feel more in tune with organizational objectives and the "big picture" behind their activities. Organizations that have completed reengineering studies have found that the current process "wait time" (which includes in-baskets, company mail, multiple levels of authorization, and so on) is a major portion of the total process time.

The second step is to ignore the physical location of information resources when initially analyzing processes. This especially applies to GIS-related data. Advances in relational databases, telecommunications networks and distributed processing systems 
make distinctions between centralized and widely dispersed operations less of a consideration. Indeed, because much of a utility's customer and facility information is geography-based, GIS technology can act as a core technology around which ihe array of other utility business systems can be integrated.

The third step is to coordinate activities rather than consolidate results at the end of the process. In many instances, separate groups within a utility perform different activities that eventually must come together. Having many units complete work simultaneously may appear to save time, but when those activities are brought together, frequently the entire process falls apart. Many utilities are looking to increase coordination by integrating the work, throughout the process, to ensure that the work is synchronized with the end goal. Here, too, using an integrated GIS facilitates the sharing of data and increases the likelihood that goals will be maintained throughout the project cycle.

The fourth step is to redesign processes to empower individuals with decisionmaking authority. Decision makers are often not the same people who complete the work. Progressive organizations assume--even expect-that individuals can make many decisions. This realization is not being lost on utilities where the belief is increasingly held that workers should have ownership of the business processes to which they contribute. When doers manage and control their work, the need for some oversight and approval functions may be eliminated.

The fifth step is to eliminate redundant data capture. Before the advent of computer processing and database storage capabilities, it was often more efficient for more than one department to collect the same information. Database technologies and improved network

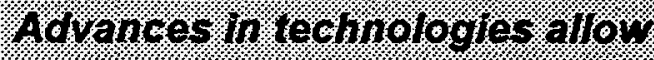

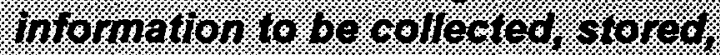

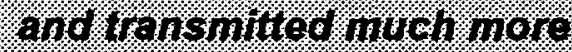
ofroten10\% communications now make this concept obsolete. Advances in technologies allow information to be collected, stored, and transmitted much more efficiently. 


\section{Reducing Headcount vs. Pursuing Fundamental Change}

Well intentioned headcount reduction and productivity improvement efforts have driven information technology acquisitions in the past. However, that approach may be short-sighted for a utility looking for value in a long-term information technology implementation, such as GIS or related technologies like document imaging and work management systems. Over the past several years, many utilities have cut staffing levels to the point that it may not be practical to justify and support an information technology investment with further reductions. Limiting the reengineering effort to the confines of reducing staff without fundamentally changing the organization may cause the real value to be lost. Through reengineering efforts, implementation may be supported based on the measurable benefits realized by "redeployment" of staff and other resources to better serve internal (that is, department-to-department) and external customers.

Information technology solutions like GIS are being developed at utilities with workflow analyses and process improvements as the focal point for realizing true investment value. These process improvements lead directly to enhancing the value customers place on the utility's product or services. When

intormation technology solutions. IThe GIS are being developed at utilities with worthlow analyses and process improvements as the tocat point for realizing true investment value.

examining a workflow, the basic

questions to be answered include: Are the products and/or services of this workflow enhancing the organization's ability to meet its basic business objective? How is information collected, accessed, utilized and maintained in the workflow? What inaccuracies, redundancies, and inefficiencies are there with existing digital or paper records? What is the lowest level in the organization where the decisions should be made? 
Many records problems are the result of workflows that have evolved incrementally without disciplined, careful evaluation of the information management needs of the workflow. Historically what has resulted is more forms and procedures, which further compounds rather than solves information problems. Implementing a new information technology like GIS offers a significant opportunity to reinvent processes and to redeploy existing resources in innovative ways rather than simply emulate outdated, inefficient strategies.

\section{Reengineering with GIS}

Reengineering with respect to an GIS should encompass the broad use of the system's products inside and outside the organization, as well as how the system relates to other technologies. For example, many organizations are in the process of rebuilding or implementing a Work Management System (WMS, that is, job scheduling and tracking) and are also investigating document imaging technology to improve paper records management. Implementing these technologies independently, without a thorough understanding of how the information managed by them is utilized in a workflow, can minimize or detract from the total potential system value. Without clearly demonstrating how these technologies positively impact a critical business mission through support of a workflow - such as those that support service reliability or new service provision - databases, applications, and hardware may not be optimized.

For example, how much additional revenue could be generated by a gas utility if an information technology solution helped it reduce the time required to place service facilities for a new subdivision? Would the builder be willing to pay a premium service fee for this improved service? What other sources of revenue could be identified by extending the reengineering process beyond traditional boundaries? How does the system support basic services provided by the organization, including the utility's marketing department? 
A number of factors have influenced the evolution of today's utility work processes and related information systems. Understandably, the change implicit in reengineering will not be accomplished in short time frames. The path of data from receipt of a service call to providing service is complex, involving many uses by a diverse variety of job functions. Data indexing, or "referencing," differs dramatically between manual work processes and reengineered automated

fiow the data path is reengineered: will directly ingact the oroanizations ability to impiovo its bastic sonvices and as a result reallze value from GIS.

processes. A key challenge in GIS implementation lies in developing "spatial" indexes to better support data use. How the data path is reengineered will directly impact the organization's ability to improve its basic services and--as a result--realize value from GIS.

While much focus is given to technical challenges involved in implementing an information system, process reengineering addresses human issues--culture, skills, communications, job functions. Clearly, this is no trivial undertaking.

This new capability of information systems like GIS to change what is done as opposed to how it is done parallels recent changes in management philosophy. Several years ago, many organizations became advocates of TQM, which essentially sought to improve services provided to customers by improving the processes required for service delivery. More recently, management literature has focused more on reengineering, which is defined as "the fundamental rethinking and radical redesign of business processes to achieve dramatic improvements in critical, contemporary measures of performance, such as cost, quality, service, and speed (emphasis added)."1

Information systems and highly specialized technologies and data sets like GIS now have the capability to support those radical redesigns and to support strategic

\footnotetext{
${ }^{1}$ Michael Hammer and James Champy, Reengineering the Corporation: A Manifesto for Business Revolution (New York, NY: Harper Business, 1993), 32.
} 
business decisions. In the fast-paced, newly competitive environments that utilities now face, radical redesign and effective strategic decision making will be requisites for survival. 


\section{CHAPTER SEVEN}

\section{REGULATORY ISSUES}

At one time, the issues surrounding the regulatory treatment of investments in information systems by regulated utilities were fairly simple and constrained by the well-developed practice of ratebase/rate-of-return regulation. Today, the regulatory treatment of information system investments is more complex and conditioned on the type of regulatory regime. Some utilities still operate under traditional forms of regulation, some operate under "alternative" forms of regulation, and others are in transition between regulatory and competitive environments. In this chapter; we consider some of the regulatory issues involved for information system investments in each of these environments.

\section{Traditional, Ratebase/Rate-of-Return Regulation}

Under traditional, ratebase/rate-of-return regulation, regulators have two general options for treatment of information system investments. They can include the investment in the ratebase as a capital investment, or they can expense it, either in a single year or across several years. Investments included in the ratebase earn a rate of return, like investments in other long-term capacity. Those that are expensed merely capture expenditures on a dollar-for-dollar basis.

Utilities, in general, would prefer to include the investment in information systems in the ratebase and earn a return on it. ${ }^{1}$ If items are to be expensed, utilities would prefer short depreciation lives and rapid recovery.

${ }^{1}$ Though utilities typically will prefer to have assets included in the ratebase so that they can earn a return on their investments, there may be reasons for seeking a different type of regulatory treatment. These include concerns over regulatory lag and heightened regulatory scrutiny of ratebase assets. 
Today, expensing the substantial costs of information systems in a single year may be less appropriate because of the increased costs of information systems. However, regulators still may prefer to expense nontraditional utility expenditures (i.e., those that are not regular and recurring operating expenses) through depreciation rather than including them in the ratebase and allowing them to earn a rate of return.

States may follow the federal agencies treatment of information systems unless grounds for departure can be demonstrated. Discussions with staff of the Federal Energy Regulatory Commission (FERC) indicate that there is no hard and fast rule as to how computer technology-based systems should be treated. As a general rule, computer hardware and software that demonstrate future benefits for the system can be capitalized as intangible plant. In telecommunications, the regulatory treatment of computer-based technologies is better defined since recent telecommunications infrastructure investments have been dominated by computer technology. Discussions with staff of the Federal Communications Commission (FCC) indicate that the FCC allows capitalization on computer hardware costing more than $\$ 500$. Initial software development and right-to-use costs are to be capitalized while operations software is to be expensed. ${ }^{2}$

To determine whether an investment is eligible for ratebase treatment, regulators must determine that the investment is used and useful. Today, many commissions look to a broad concept of used and useful and whether the investment is needed and economically desirable. Furthermore, investments with benefits that are known and quantifiable, inure to the benefit of ratepayers, and

Future period recoven poses: unique regulation challenge in that the benefits, particulany those: related to new technologies, nay be perceived as more speculative than iraditional ratebase investments and may be subject to nore challenge. and scrutiny.

\footnotetext{
${ }^{2}$ Geographic Information Systems are comprised of software, hardware, and data conversion. Each component may receive different regulatory treatment. Typically, utilities will capitalize data conversion which have life cycles of $\mathbf{2 0}$ to $\mathbf{5 0}$ years. Software and hardware will have substantially shorter economic lives which may lead the utility to seek different treatment.
} 
provide a legitimate utility function may qualify. For future benefits, the benefit amount is compared on a net present value basis with the cost of the system. Future period recovery poses a unique regulatory challenge in that the benefits, particularly those related to new technologies, may be perceived as more speculative than traditional ratebase investments and may be subject to more challenge and scrutiny.

Even if an investment is placed in the ratebase, the regulatory commission must still decide how much of it to put in the ratebase. That determination is done through prudency review. Prudency reviews are intended to ensure that any fraudulent, unwise, or extravagant outlays should not be a burden on ratepayers. ${ }^{3}$

Prudency reviews are particularly sensitive in the case of technologies where regulators have experienced cost overruns of systems and found utilities at fault for lack of management control over allocation of costs to the systems. In addition, advanced technologies may be challenged for excessive built-in

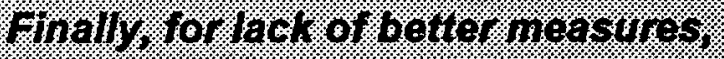

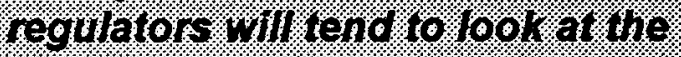
comparabilit or the cost of the

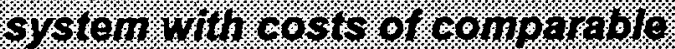
systems tor comparablo willites. obsolescence; some regulators may want to know that the technology has the ability to migrate to next-generation technology. Finally, for lack of better measures, regulators will tend to look at the comparability of the cost of the system with costs of comparable systems for comparable utilities. Prudency typically is determined after the investment is made, but regulators may apply the concept of prudence in any prereview of an investment or set standards for prudency in any eventual recovery. ${ }^{4}$

Further complexities for the treatment of utility investments in information systems for those utilities under traditional forms of regulation are the separation of costs and benefits between interstate and intrastate operations, the determination of

${ }^{3}$ In re Municipality of Anchorage d/b/a Anchorage Telephone Utility, 111 Pub. Util. Rep. 4th (PUR) 524,525 (Al. 1989).

4 In re North Carolina Power, 142 Pub. Util. Rep. 4th (PUR) 117, 139-140 (N.C. 1993). 
the length of time over which an item will be depreciated, and the allocation of costs and benefits between regulated and unregulated business segments.

\section{Alternative Forms of Regulation}

Alternative forms of regulation are emerging in the stead of traditional ratebase/rate-of-return regulation. These alternative forms of regulation should provide efficiency incentives, innovation incentives, pricing flexibility, administrative efficiency, adequate returns to investors, fairness, quality of service, rate predictability, and consistency. ${ }^{5}$ These types of alternative regulatory structures range from minor variations on rate-of-return regulation to complete deregulation!.

The two principal alternative forms of regulation, which fall short of deregulation, are incentive regulation and price-cap regulation. Incentive regulatory structures typically work within rate-of-return regulation, giving the utility certain rewards for achieving results the regulator, and ostensibly the public, desires. Price-cap structures depart from rate-of-return regulation, allowing the utility the flexibility to operate within price bands or under a price cap. Though price-cap regulation departs further from ratebase/rate-of-return regulation than incentive regulation, it still relies on rate-ofreturn regulation to set benchmarks, bands, or caps.

Under incentive regulation, inclusion of past utility investments in the utility's ratebase is important to the utility, since rate-of-return regulation and the earning on the ratebase will continue to be closely related to incentive regulation. However, as incentives are added to the structure, more flexibility will be

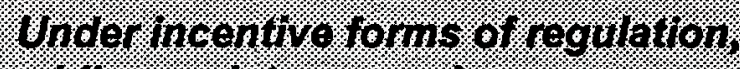

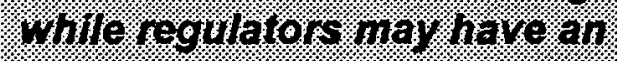

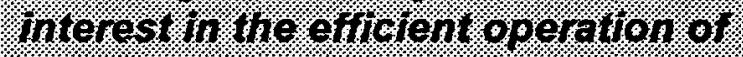
Hovitity anolin tho proviston of

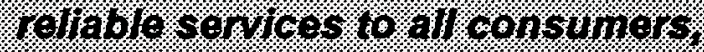

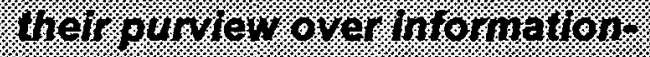

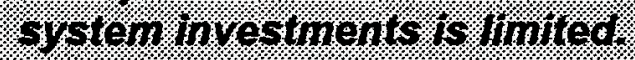

${ }^{5}$ Roger A. Morin, Regulatory Finance: Utilities Cost of Capital (Arlington, VA: Public Utilities Reports, Inc., 1994), 489-490. 
available to the utility to deploy investments. For example, the regulatory commission might set the revenue requirement for the utility (which would include earnings on the ratebase) and might establish an incentive structure through which the utility could earn more money if it could lower its cost of service or improve its service compared to market benchmarks. Typically under incentive regulation, the utility is able to retain a share of the savings over and above its return on the ratebase. Thus, under incentive regulation the utility will make internal return calculations on how and where to deploy its assets, including information systems, and how to account for their costs. Under incentive forms of regulation, while regulators may have an interest in the efficient operation of the utility and in the provision of reliable services to all consumers, their purview over information-system investments is limited.

Under price-cap regulation, regulators are even less involved in utility investment decisions than under incentive regulation. The regulatory treatment of utility information system investments is only important initially as regulators set price caps or price-cap bands.

Under both incentive regulation and price-cap regulation, utilities may attempt to position themselves by acquiring advanced technologies through ratepayer funding prior to the full implementation of the incentive or price-cap system. Other challenges for utilities will include optimizing information system investments; replacing costly, less efficient, less timely processes with new processes, which employ

Under both incentive regulation and price-cap regulation, utilities may. attempt to position themselves by acquiring advanced technologies: through ratepayer funding prior to the full implementation of the incentive or price-cap sy stem. sophisticated information systems;

using information systems to improve service quality; and using information systems to cut costs and improve the utility's strategic, competitive situation. Challenges for regulators include the establishment of appropriate baselines, incentive structures, and price caps; insuring the maintenance of service quality (which can be positively 
impacted by the effective use of information systems or negatively impacted by faulty implementation or inappropriate systems); encouraging utilities to use information systems to maximum advantage; and separating the costs of information system investments between utility business segments under traditional regulation and those under alternative forms of regulation.

\section{Transition to Competitive Markets}

A major theme of this report is that information systems, like GIS, have the capability to assist utilities become more efficient and responsive to consumer needs. Ultimately, in a competitive environment utilities will have to make their own investment decisions

Regulators nay make he oest vise or

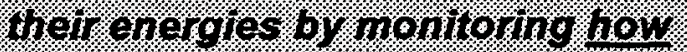

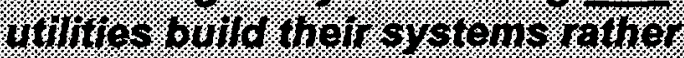

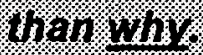

independent of regulatory oversight. In

the transition, however, regulators will still be involved in those decisions.

Some would argue that regulatory commissions have no business becoming involved in, or even being concerned about, a utility's competitive operations. They would say that regulators should be wary of utilities trying to load costs on the regulated portions of the business and away from the competitive portions. They would require that investments in information systems wholly benefit existing customers. ${ }^{6}$

It will be difficult, if not impossible, to separate the benefits of information systems into those that serve the interests of captive ratepayers and those that position the utility to compete in a new environment. A GIS that allows the utility to quickly identify and repair service outages is both an improvement in services for captive

\footnotetext{
${ }^{\top}$ This debate is raging not only for information systems, but also for facility investments, such as installation of fiber optic networks. Even though such a network may have significant capacity beyond that needed to serve the consumer and may provide a competitive advantage to the utility deploying the network, the investment may still be regarded as used and useful in meeting the regulated service needs of the customer.
} 
customers and a competitive tool. Even a GIS with a marketing component cannot be isolated as a competitive weapon if it identifies potential new customers and thereby benefits existing ratepayers by spreading fixed costs. Utilities under traditional, ratebase/rate-of-return regulation will argue to regulators that investments in information systems will provide higher quality services to customers and reduce customer costs. Little mention will likely be made of strategic advantages or competitive benefits.

Regulators may make the best use of their energies by monitoring how utilities build their systems rather than why. For a utility with competitive and rate-regulated business segments, appropriate cost allocation between the segments is a legitimate concern. Comparison of the costs of information systems can be made between like utilities, and regulated customers should be charged for only reasonable costs. Costbenefit analyses, like those discussed earlier in this report, must be in place before regulators authorize information system costs to be expensed or added to the ratebase.

For the regulatory commissions themselves, geographic boundaries are shifting, proliferating, and overlapping. In telecommunications, for example, local exchange carrier boundaries are not the same as cellular boundaries, personal communications services boundaries, or LATA boundaries. As a result, information systems that incorporate geographic information may become even more useful for regulatory commissions. 